\title{
Effect of 3D stall-cells on the pressure distribution of a laminar NACA64-418 wing
}

\author{
Daniele Ragni $^{1} \cdot$ Carlos Ferreira $^{1}$
}

Received: 22 January 2016 / Revised: 27 June 2016 / Accepted: 4 July 2016 / Published online: 23 July 2016

(C) The Author(s) 2016. This article is published with open access at Springerlink.com

\begin{abstract}
A 3D stall-cell flow-field has been studied in a 4.8 aspect-ratio wing obtained by linear extrusion of a laminar NACA64-418 airfoil profile. The span-wise change in the velocity and pressure distribution along the wing has been quantified with respect to the development of cellular structures from $8^{\circ}$ to $20^{\circ}$ angle of attack. Oil-flow visualizations help localizing the regular cellular pattern in function of the angle of attack. Multi-plane stereoscopic PIV measurements obtained by traversing the entire setup along the wing span show that the flow separation is not spanwise uniform. The combination of different stereoscopic fields into a $3 \mathrm{D}$ volume of velocity data allows studying the global effect of the stall-cell pattern on the wing flow. Integration of the experimentally computed pressure gradient from the Navier-Stokes equation is employed to compute the span-wise distribution of the mean surface pressure. Comparison of the results with the ones obtained from pressure taps installed in the wing evidences a span-wise periodic loading on the wing. The periodic loading has maxima confined in the stream-wise direction between the location of the highest airfoil curvature and the one of the airfoil flow separation. Estimation of the periodic loading is found within 2-6\% of the sectional wing lift.
\end{abstract}

\section{List of symbols}

$(u, v, w)$ Cartesian-velocity components along the stream-wise, wall-normal and out-of-plane directions

Daniele Ragni

d.ragni@tudelft.nl

Aerodynamics, Wind-Energy and Flight Performance and Propulsion AWEP Department, TU Delft Aerospace Faculty, Kluyverweg 1, 2629 HS Delft, The Netherlands $(x, y, z) \quad$ Cartesian-coordinate components along the stream-wise, wall-normal and out-of-plane directions

$\alpha \quad$ Angle of attack of the wing $\left(^{\circ}\right)$

$\delta \quad$ Discrete difference

$\bar{f} \quad$ Mean of a quantity, $f$

$\rho \quad$ Flow density $\left(\mathrm{kg} \mathrm{m}^{-3}\right)$

$A \quad$ Planform area of the wing, $s \times c(\mathrm{~m})$

$A R \quad$ Wing aspect-ratio, $s / c$

$c \quad$ Wing chord, profile chord (m)

$c_{d} \quad$ Drag coefficient, obtained as: $\frac{D}{1 / 2 \rho V_{\infty}^{2} A}$

$c_{l} \quad$ Lift coefficient, obtained as: $\frac{L}{1 / 2 \rho V_{\infty}^{2} A}$

$c_{m} \quad$ Pitching-moment coefficient, obtained as: $\frac{M}{1 / 2 \rho V_{\infty}^{2} A c}$

$c_{p} \quad$ Pressure coefficient, obtained as: $\frac{p-p_{\infty}}{1 / 2 \rho V_{\infty}^{2}}$

D Wing drag (N)

$d \quad$ Lens diameter ( $\mathrm{mm})$

$f \quad$ Lens focal length ( $\mathrm{mm}$ )

$f^{\prime} \quad$ Fluctuations of a quantity, $f$

$f \# \quad$ Lens aperture, fld

$h \quad$ Test-section height (m)

$L \quad$ Wing lift (N)

$l \quad$ Test-section length (m)

$M \quad$ Wing pitching-moment ( $\mathrm{N} \mathrm{m}$ )

$n \quad$ Stall-cell number

$p \quad$ Static pressure $(\mathrm{Pa})$

$p_{\infty} \quad$ Free-stream static pressure $(\mathrm{Pa})$

$s \quad$ Wing span (m)

sgn Sign of a variable, $f /|f|$

St Strouhal number, defined as $v c / V_{\infty}$, where $v$ is the characteristic frequency of the vortex-shedding in the flow

Wing/airfoil thickness per chord percentage 
$V \quad$ Velocity vector with Cartesian components, $u, v, w\left(\mathrm{~m} \mathrm{~s}^{-1}\right)$, along the stream-wise, wall-normal and out-of-plane directions, $x, y, z(\mathrm{~m})$

$w \quad$ Chord-normalized distance between the separation line and the stall-cell vortex axis

$x_{s} \quad$ Coordinate tangential to the airfoil profile (m)

2C Two-component

2D Two-dimensional

3C Three-component

3D Three-dimensional

CNC Computer numerical control

LE Leading edge

LTT Low-turbulence wind tunnel

PIV Particle-image velocimetry

Re Reynolds number, defined as: $\frac{\rho V_{\infty} c}{\mu}$

TE Trailing edge

\section{Introduction}

\subsection{Stall-cells in airfoils}

The onset of stall has been extensively studied in many aerodynamic applications, ranging from wind-turbine blades to axial compressors. One of the most critical aspects of stall is the abrupt change in the aerodynamic performance of many devices, resulting into a sudden change of lift and drag caused by flow separation. Airfoil-flow stall (Clancy 1975) is conventionally approximated with a uniform separation front and measured neglecting any three-dimensionality effect in several wind-tunnel models. This simplification is rarely verified during experimental campaigns, due to the frequent reorganization of the flow separation into a more complex 3D cellular pattern (Boiko et al. 1996), accompanied by radical changes in the lift and drag of the wing itself. Early literature studies from Gregory et al. (1971) and from Weihs and Katz (1983) have shown that in low aspect-ratio wings, predominantly generated by extrusion of a laminar airfoil, the separated flow at the trailing edge reorganizes in a three-dimensional pattern of cellular structures. The authors point out that the three-dimensionality of the flow can lead to a change of the airfoil performance, most importantly: the maximum lift coefficient. One of the main features of laminar airfoils under moderate angle of attack is the presence of a leading-edge separation bubble, the sudden breakdown of which, so-called bursting, determines an abrupt loss of lift and an increase in drag (Crimi and Reeves 1976; Kozlov et al. 2006). Despite its occurrence in many low aspectratio wings, it seems that the presence of such a flow feature is not affecting the topological pattern of the span-wise periodic structures. However, the burst of the leading-edge separation bubble destroys the cellular pattern, due to flow separation at the leading edge occurring at a relatively high angle of attack. As seen by Gregory et al. (1971), stallcells have been found to be rather persistent flow features already in supposedly 2D airfoil-testing. In their study, several mechanisms including extensive wall-suction were attempted to suppress the $3 \mathrm{D}$ flow pattern and to restore a uniform flow separation at the suction side of the model. In their early study, focusing on a simple flow visualization, Winkelmann and Barlow (1980) refer to such structures as mushroom-shaped or "owl's face" cellular patterns. The peculiar names are due to a pair of counter-rotating vortices with axis perpendicular to the wing planform, generated by the rearrangement of the flow separation front occurring at moderate angles of attack. Additional investigations from Winkelmann (1990) and Bippes et al. (1987) confirmed the presence of paired vortical structures developing along the wing, though not further progressing in linking their formation to the typology of airfoil separation. Although these counter-rotating vortices have been visualized in several finite-wing models, both early (Gregory et al. 1971) and more recent literature (Schewe 2001) agree in not attributing the physical origin of stall-cells to the consistent separation typically occurring at the wing tips. One of the first explanations given to the formation of $3 \mathrm{D}$ structures from a 2D separation line has been originally found in the work of Weihs and Katz (1983). In their work, they suggested that the cellular pattern is the result of a Crow-type instability, where two counter-rotating vortices mutually interact amplifying small oscillations in their shape, up to the formation of a chain of vortex rings (Crow 1970). Although this hypothesis might explain the first stage of the evolution of the vortex sheet associated with the flow separation into a three-dimensional cellular pattern, the intrinsic inviscid character of Crow-type instabilities cannot give information on the origin of the pattern, due to the presence of a viscous boundary layer and solid boundaries. Weihs and Katz (1983) still focus on the deformation of the flow separation front into a more complex pattern at a moderate airfoil angle of attack. In more recent studies (Rodriguez and Theofilis 2010), new hypotheses tend to ascribe the phenomenon to span-wise instabilities in the flow separation front, amplified by the increase in angle of attack at low Reynolds number for laminar airfoils. More in particular, the work of Rodriguez and Theofilis (2010) attributes the generation of stall-cells to the amplifications of a two-dimensional instability in the flow separation line. Elimelech et al. (2012) correct the present idea by ascribing the phenomenon to a three-dimensional span-wise instability. However, the work of Yon and Katz (1998a) refuted the previous hypothesis by acquiring pressure measurements on a wing model, being in disagreement with the presence of such an instability made out of a single vorticalline. Additionally, the latter provided extra information on 
stall-cells pattern characteristics, as for example the linear proportionality between the integer number of cells on the wing surface and their aspect-ratio, in agreement with the estimation from Winkelmann and Barlow (1980) obtained on a wing-flap few years before. More extended information is also provided by the authors on the time-scale of the cellular movement (Yon and Katz 1998a, b). Recent results from Manolesos et al. (2014) confirmed that the geometrical shape of such structures in function of the angle of attack is function of the profile characteristic. In particular, they showed that the Reynolds number has an effect on the upstream location of the separation front, while the stallcell area-growth is proportional to the increase in angle of attack and, more precisely, independent of the wing aspectratio for relatively high angles.

\subsection{Frequency content and dynamics}

Stall-cells have been found to have both a rather steady or dynamic time-response, with peculiar features dependent on the flow Reynolds number and on the characteristics of the boundary layer at their location. Yon and Katz (1998a) showed, by use of fast-responding pressure transducers embedded in a NACA0015 wing at $R e=0.60 \times 10^{6}$, that stall-cells oscillate with a dominant frequency below the one corresponding to wake instabilities, determined by the separated flow on the wing. In particular, the authors showed that low-frequency $(S t \approx 0.04)$ oscillations are associated with stall-cells, while higher-frequency contributions relate to the most common wake instabilities $(S t \approx$ $0.15)$. Additionally, their unsteady-pressure time-histories suggested that pressure fluctuations as measured at the locations of stall-cells do not have any connection with the ones associated with the wake shedding entailing that:

1. the wing shear layer determines the formation of two independent types of coherent structures: one pertaining to the shedding of the separated flow in the wake and another to the stall-cell pattern;

2. although cellular structures are found to be unsteady, their movement in time is rather limited when compared to bluff-body shedding.

The behavior of stall-cells at lower Reynolds numbers is more controversial: recent studies from Broeren and Bragg (2001) found no span-wise time-fluctuations at $R e=0.30 \times 10^{6}$, contrarily to the work of Zarutskaya and Arieli (2005), reporting rather irregular motions at $R e=0.39 \times 10^{6}$. Recent works from Rodriguez and Theofilis (2010) using bi-global linear-instability analysis showed topological similarities between laminar separation bubbles and stall-cells, in terms of modal instability-components.

\subsection{Loading distribution}

Stall-cells have been found to modify the loading distribution of airfoil wings. A first insight can be already found in the work of Yon and Katz (1998b). In their work, by analysis of pressure measurements in the attached flow region between different stall-cells, they found a wing pressure distribution corresponding to the one obtained with potential-flow calculations of the same flow at a lower angle of attack. One of the main conclusions of their study was the relevance of these differences with respect to the maneuverability of the wing once deployed in aircraft applications. This was also confirmed later by Disotell and Gregory (2015) suggesting that stream-wise vortices emanating from the stall-cell "foci" determine a consistent downwash with associated high-amplitude pressure fluctuations. When extended to airfoils and wings in dynamic regimes, Carta (1975) measured an additional non-uniform load distribution determined by these cellular flow structures, actively contributing to the presence of stall-delay. The presence of these stall-cell structures has been investigated as well in helicopter applications (Ottavio et al. 2008). In these high aspect-ratio rotating-wings, the radial flow is the driver of the instability which brings to the development of cellular structures preventing the centrifugal increase of the radial-velocity distribution up to the tip. In computational fluid dynamics, a substantial amount of research has been devoted to determine the effect on the pressure distribution and loading in low aspect-ratio wings (e.g., Zarutskaya and Arieli 2005; Taira and Colonius 2001). In particular, Taira and Colonius (2001) concluded that in low aspectratio wings, the stall-cells regime is an intermediate state which persists till the wake degenerates in a pure 2D Karman-shedding. Despite the large body of literature focusing on stall-cells dynamics, it is rather unclear what their actual effects on the wing velocity and pressure fields are. Predominantly in wind-turbine blades, currently designed on the basis of two-dimensional BEM codes (Burton et al. 2001), 2D polars from wind-tunnel tests (Selig et al. 1995, 2011) and steady computations, it is crucial to quantify the performance change with respect to a flow separation that is not span-wise uniform. Especially in modern airfoil design-solutions, where aerodynamic and structural characteristics (Ragni et al. 2014) are combined in high aspectratio blades, the determination of a 3D unsteady loading might enhance the fatigue of the wing, or even affect the resonant response of the structure once installed in a wind turbine. In this respect, the present study addresses the comparison between supposedly two-dimensional steady polars acquired with wind-tunnel pressure taps, and the three-dimensional pressure distribution computed from stereoscopic particle-image velocimetry (SPIV) velocity fields. More precisely, the manuscript aims at quantifying 
the change in the local pressure distribution due to stallcells on a laminar NACA64-418 wing, reference profile for several wind-turbine and helicopter applications. An oilflow investigation of the NACA64-418 wing is carried out followed by a SPIV characterization of the span-wise flow field. Vector fields in planes parallel to the mid-span one have been combined to form a volume of data. The procedure has been found in recent studies to be relatively useful in the quantification of the size and characteristics of the stall-cells pattern (Manolesos et al. 2014). The experimental velocity fields are subsequently used as input in the Navier-Stokes equations in a similar effort as in Noca et al. (1999), van Oudheusden et al. (2007), Ragni et al. (2012), to obtain the pressure gradient directly integrated into flow pressure, further compared to pressure taps installed in the wing model.

\section{Experimental model and wing performance}

\subsection{Wind-tunnel and airfoil model}

A NACA64-418 airfoil with chord $c=25 \mathrm{~cm}$ and chordnormalized thickness $t / c=18 \%$ has been manufactured into an aluminum wing of span $s$ equal to the height of the wind-tunnel test section $h$ of $1.25 \mathrm{~m}$ and aspect-ratio $A R=$ $h / c=4.8$. In Fig. 1, the coordinates of the laminar airfoil profile NACA64-418 are presented together with a picture of the wing in the test -section. The wing has been manufactured by computer numerical control (CNC) machining, with a final roughness below half a micron. The model has been vertically installed in the closed-circuit low-turbulence wind tunnel (LTT) of the TU Delft laboratories. The wind tunnel has an octagonal test section with $1.80 \mathrm{~m}$ width, $1.25 \mathrm{~m}$ height and $2.60 \mathrm{~m}$ length. With a contraction ratio of 17.6 , the wind tunnel can reach a maximum wind speed of $120 \mathrm{~m} \mathrm{~s}^{-1}$ with a turbulence level ranging within 0.07 to $0.15 \%$ in wind speeds from 10 to $75 \mathrm{~m} \mathrm{~s}^{-1}$. The model has been supported in the tunnel section by a six-component balance able to measure steady lift, drag and pitching moment. A series of 52 pressure taps ( 24 on the bottom surface and 28 on the top one) have been installed in the wing. The chord-wise location of the pressure taps is indicated in Fig. 1b. The orifices have been located on a plane inclined of $15^{\circ}$ with respect to the mid-span one, in order to ensure interference-free measurements. All pressure taps have been connected to a scanni-valve able to sample the entire pressure distribution at a frequency of about $2 \mathrm{~Hz}$, allowing for the acquisition of the average pressure on the airfoil surface. A measurement acquisition time of about 3 min per angle of attack has been chosen in order to have ensemble averages with at least 350 samples.

\subsection{Airfoil lift and drag performance}

Aerodynamic loads have been measured in a range of angles of attack from $-20^{\circ}$ to $+30^{\circ}$, at a free-stream velocity of $V_{\infty}=60 \mathrm{~m} \mathrm{~s}^{-1}$, corresponding to a Reynolds number of $R e=10^{6}$. The airfoil characteristics lift/drag/pitching moment are shown in Fig. 2 as obtained from the six-component balance in both free and forced boundary-layer transition. Boundary-layer transition has been forced with two different serrated tapes: a first configuration with $0.32 \mathrm{~mm}$ serrated tape
Fig. 1 a NACA64-418 wing model installed in the wind-tunnel test section. b NACA64-418 profile and chord-wise location of the pressure ports on the wing model
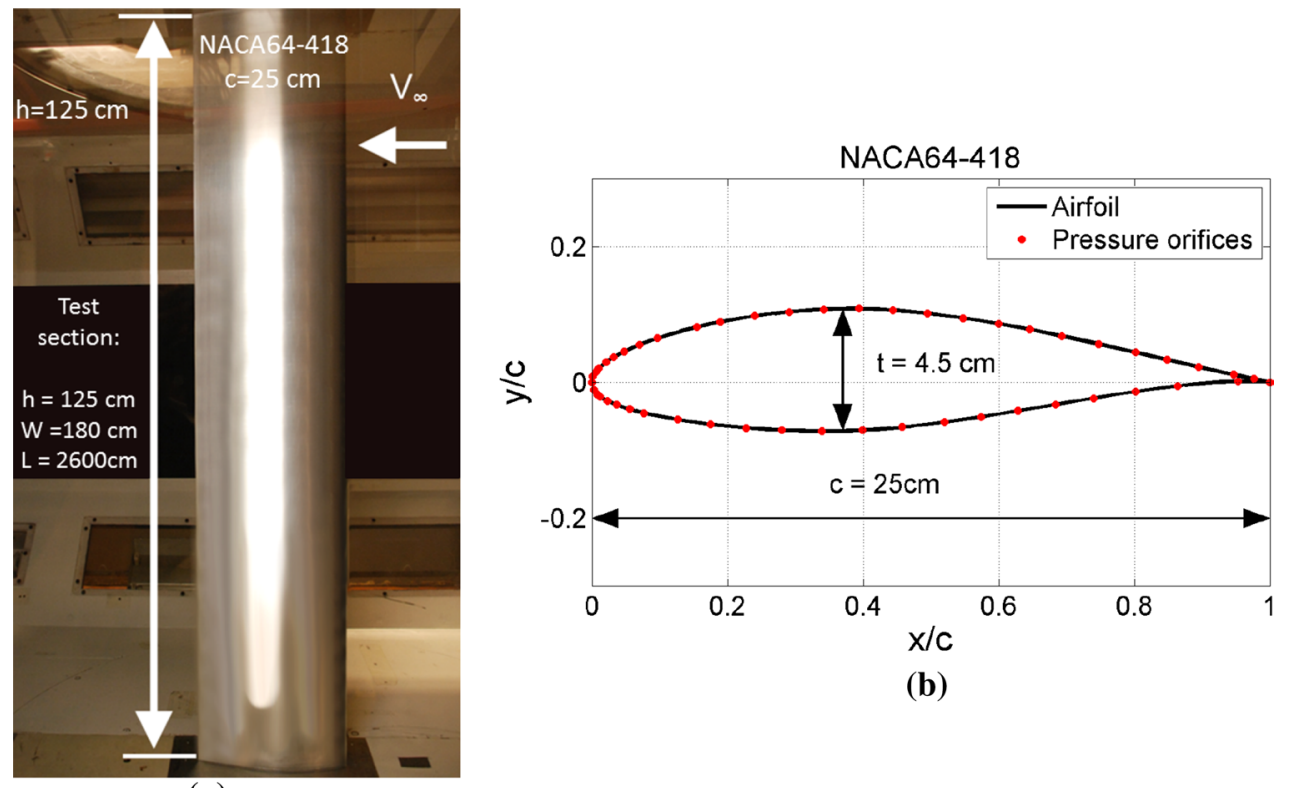

(b)

(a) 

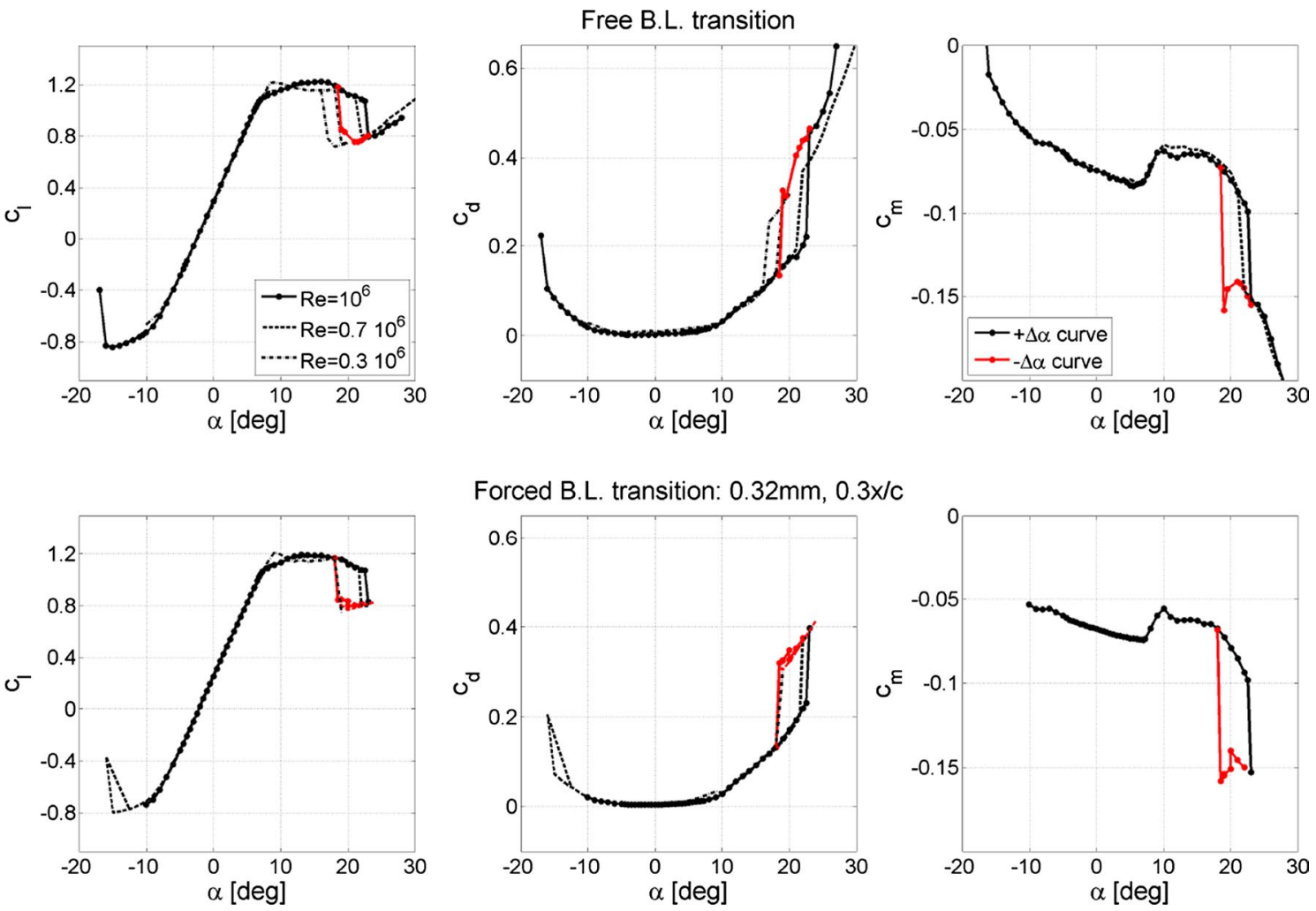

Forced B.L. transition: T.S. $=0.20 \mathrm{~mm}, 0.05 \mathrm{x} / \mathrm{c} ;$ B.S. $=0.32 \mathrm{~mm}, 0.10 \mathrm{x} / \mathrm{c}$
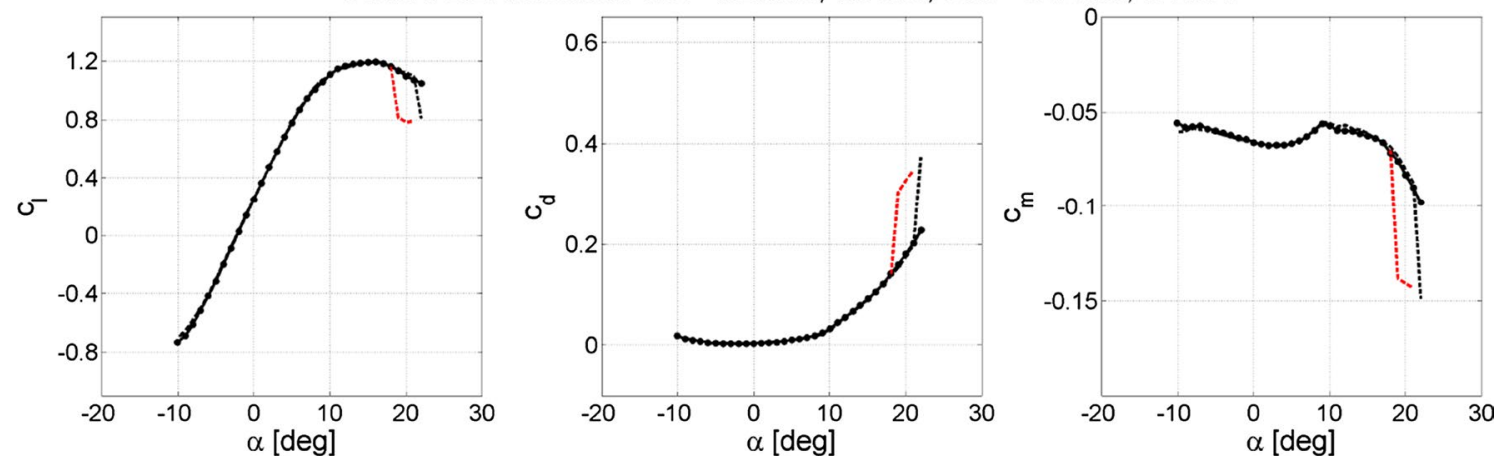

Fig. 2 Lift/drag/pitching-moment coefficient obtained from six-component balance measurements, NACA64-418 wing with $A R=4.8$, results for $R e=10^{6}, 0.7 \times 10^{6}, 0.3 \times 10^{6}$. Top row free boundarylayer transition. Middle row forced boundary-layer transition with $0.32 \mathrm{~mm}$ zigzag tape $\left(6 \mathrm{~mm}\right.$ width, $30^{\circ}$ angle) placed at $x / c=0.30$

( $6 \mathrm{~mm}$ width, $30^{\circ}$ zigzag angle) placed at $x / \mathrm{c}=0.30$ on both surfaces and a second configuration with $0.20-\mathrm{mm}$ serrated tape at $x / c=0.05$ on the top surface and $x / c=0.10$ on the bottom one. The particular choice of the previous dimensions has been based upon the work of Braslow and Knox (1958) and later of Selle (1999), prescribing the most effective turbulator height in order not to have a relevant modification of the airfoil performance. Measurements with free boundary-layer transition have been acquired by keeping the airfoil in the original clean condition. Results show that the steady lift and drag on both top and bottom surfaces. Bottom row forced boundary-layer transition with $0.20-\mathrm{mm}$ zigzag tape $\left(6 \mathrm{~mm}\right.$ width, $30^{\circ}$ angle) placed at $x / c=0.05$ on the top surface and $x / c=0.10$ on the bottom one. Black airfoil polars as obtained by one-directional pitching of the airfoil; red airfoil hysteresis cycle

polars are independent of the Reynolds number for values larger than $R e=0.7 \times 10^{6}$. The typical linear behavior of the lift coefficient is measured between $-9^{\circ}$ and $7^{\circ}$. In this range of angles of attack, small Reynolds effects are appreciated, besides a considerable reduction of the max-lift angle of attack for the curve at $R e=0.3 \times 10^{6}$. This is coherent with the typical behavior of laminar airfoil profiles, having a laminarflow separation bubble sharpening the response at maximum lift and abruptly causing leading-edge flow separation due to its bursting at high angle of attack (Hu and Zifeng 2008). The 
full flow separation on the top surface is measured at about $22^{\circ}$ angle of attack with a hysteresis cycle which restores the original airfoil performance when pitching down to $18^{\circ}$. At lower Reynolds, the hysteresis cycle extends to a relatively larger angle of attack. This indicates that the airfoil curvature close to the leading-edge location is such that the flow on the airfoil surface needs a more favorable pressure gradient to reestablish its original performance. Measurements pertaining to the wing operating with forced boundary-layer transition do not show an important degradation of the laminar airfoil performance, though a clear anticipation of the nonlinear regime is visible in both curves of the lift and drag coefficients, as expected by the earlier reenergization of the boundary layer induced by forced transition. Forcing of the boundary layer seems to interfere with the role of the separation bubble allowing for a less pronounced change of all airfoil curves at high angles of attack. Previous studies from Boiko et al. (1996) confirmed that the lift and drag coefficients of such airfoil result from a flow field that combines both the leading-edge separation bubble and the stall-cells. The first flow feature acts mostly at the wing leading edge where the curvature is max, therefore showing the largest contribution on the maximum $c_{l}$. Despite this fact, Boiko et al. (1996) showed that by actively operating through acoustic disturbances in the separated-flow region, a more prominent effect of the 3D reorganization of the stall-cell flow can be made on the pressure distribution. In the following section, the characteristic of such flow features for angles of attack corresponding to the ones in Fig. 2 will be analyzed and discussed.

\section{Organization of stall-cells in a NACA64-418 wing}

Stall-cells develop in the form of three-dimensional elongated structures, typically localized in a "mushroom"-like type shape (Winkelmann and Barlow 1980; Winkelmann 1983). The span-wise elongation and size of these structures depend upon the pressure gradient in the separatedflow region, function of the airfoil characteristics, such as angle of attack and Reynolds number (Manolesos et al. 2014). In this section, a schema of the flow features pertaining to the NACA64-418 laminar profile is given. The origin of stall-cells is determined by the reorganization of the separation front of the wing, which can be seen in the combined schema/results in Fig. 3. Flow fields pertaining to wings with laminar airfoil profiles typically show a small separation bubble close to the leading edge of the wing. Besides footprints in the oil-flow visualizations, results from the present study show a more predominant effect of this small separation bubble in the pressure orifices data. In the close vicinity of the leading edge of the wing, the oil-flow visualizations suffer from high curvature and photographic-reflections effects. The origin of cellular structures spatially locates in the reorganization of the separation front (Fig. 3) which extends up to the entire wing span. It has to be noted that in the literature the separation front is typically referred to as a laminar one; however, several studies report that the stall-cell formation mechanism is not affected by the turbulent enforcement of the boundary layer before the flow separation (Gregory et al. 1971). However, this dependency is true as long as the turbulent transition does not affect the flow at the separation bubble, which develops upstream the stall-cell pattern.

The separation front from a span-wise uniform flow feature transforms into a cellular pattern alternated with stall-cells and stagnation points (so-called focix) as shown in Fig. 3. In the following section, a more detailed analysis of the flow field is carried out with oil-flow visualizations. Results are presented for the NACA64-418 wing at $R e=10^{6}$ under free boundary-layer transition.
Fig. 3 Schematic of the stall-cell flow pattern on the NACA64-418 wing with $A R$ $=4.8$, based on results for $\alpha=13^{\circ}, R e=10^{6}$. Pattern in agreement with studies from Boiko et al. (1996) and Rodriguez and Theofilis (2010)

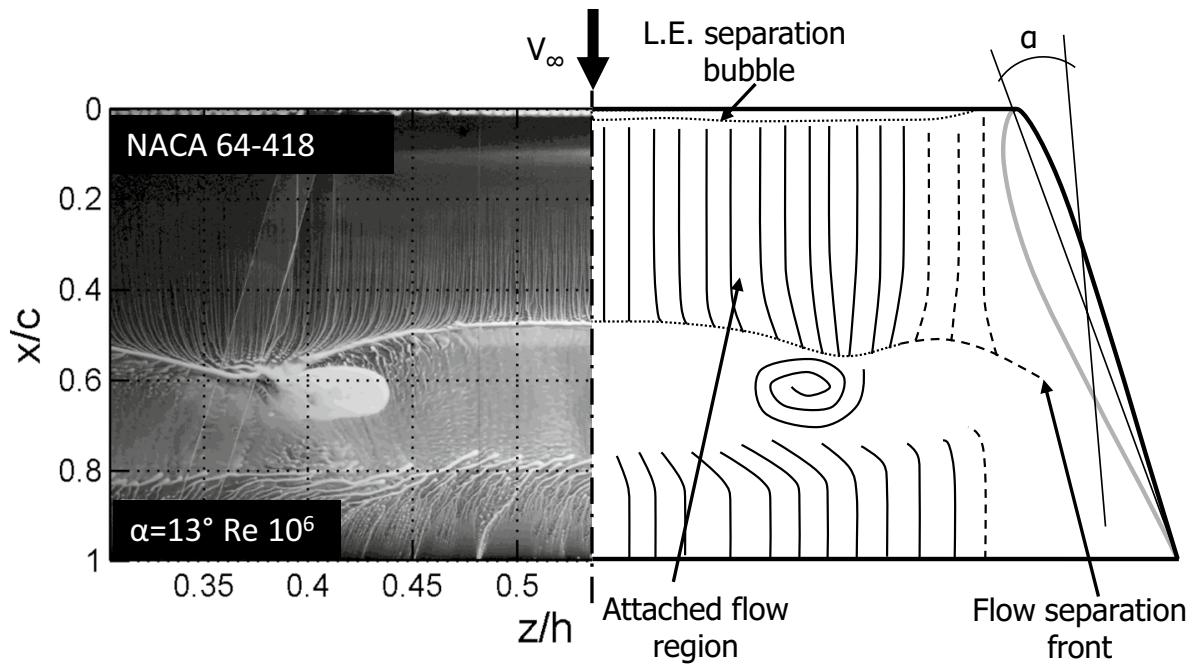




\subsection{Oil-flow visualization of stall-cells in a NACA64-418 wing}

The stall-cell flow-organization is visualized in function of the angle of attack for the NACA64-418 wing. Oil-flow visualizations are presented in Fig. 4, obtained by acquiring images of the airfoil surface painted with a fluorescent mixture and illuminated with diffused ultraviolet light. The mixture is obtained from 50-mm liquid-paraffin wax and 15-25 drops of fluorescent-oil additive A-680 from (UVP, INC. San Gabriel, CA., USA). Illumination is provided by an ultraviolet lamp from Labino type PS 135 UV. Images are acquired with the wing in a steady configuration, where the angle of attack is set in a range from $0^{\circ}$ to $20^{\circ}$ at $R e=10^{6}$. The recording camera is placed at a $90^{\circ}$ angle with respect to the wing planform. A thirdorder polynomial calibration is applied in order to map the curved surface of the airfoil into a straight span-wise plane of dimension $c \times s$. Results in Fig. 4 identify the cellular structures on the airfoil wing in function of a static airfoil angle of attack, at a Reynolds number of 1 million. The number of cellular structures presented on the wing has been compared to two empirical formulas derived from previous literature. According to Crow's (1970) theory, the integer number of stall-cells is solely function of the wing aspect-ratio: $n=A R / 2.28$. A more complex formula can be found in the study from Boiko et al. (1996): $n=A R / 17.2 \times k \times \tan (\alpha)$, where $A R$ is the wing aspectratio, $\alpha$ is the angle of attack at which the flow separation is seen for the first time, $k$ is the chord-normalized distance between the separation line and the stall-cell vortex axis.

The first formula with wing aspect-ratio of 4.8 gives a resulting Crow's predicted integer number of 2 stallcells per wing span, while with separation angle of $8^{\circ}$ and about $20 \%$ chord distance between the separation line and the stall-cell vortex axis, a single "vortex pair" (socalled by the authors) is obtained with the second formula for all angles of attack. The beginning of the instability can be seen at $9^{\circ}$, when the separation line buckles from an approximately straight pattern into a stall-cell one at a chord-wise location of about $x / c=0.8$ (Fig. 4b). The formation of stagnation nodes in the wing surface (Boiko et al. 1996) appears from $11^{\circ}$ angle of attack, as shown by the abundant collection of oil in the stagnation region. The presence of multiple nodes in the wing span with a spacing of $0.20 h$ is a result of the development of the separation front into a three-dimensional pattern, with oil recirculation zones at the nodes location. By increasing the angle of attack from $9^{\circ}$ to $13^{\circ}$, the distance between two different stagnation zones increases up to about $0.30 h$, distance kept till the separation reaches the leading edge of the airfoil. The reduction of the stagnation size in the same range of angles of attack proves that the three-dimensional pattern is dependent to the amplitude of the suction region on the top surface. In order to confirm that the stall-cell pattern is not the result of a boundary-layer trigger to turbulent flow, the flow has been locally forced with a strip of tape of $0.2 \mathrm{~mm}$ thickness and $6 \mathrm{~mm}$ inclined at about $15^{\circ}$ along the chord direction at about $0.30-0.35$ span-wise location (traces of it can be seen from photographic reflection in the oil-flow images). The characteristics of the tape are in the range specified by Braslow and Knox (1958) to force the transition of the boundary layer to turbulent (from 0.07 to 0.47 $\mathrm{mm})$, though no effect on the stall-cell pattern is found, in agreement with the previous literature. In Fig. 5, the flow around two consecutive stall-cells has been imaged in time to show the progressive accumulation of oil in the stagnation region, giving additional information on the sense of rotation of the flow in the zone. Although not being a timeresolved oil-flow visualization, Fig. 5 has been obtained by setting the angle of attack to $12^{\circ}$ and by operating the wind tunnel from zero velocity to the operational regime in a relatively short time (within 3-5 s). Just after having reached operating conditions, the progressive accumulation of oil has been photographed at regular intervals of about $5 \mathrm{~s}$, in order to see the development of the separation front into a stall-cell. The development of the flow pattern in Fig. 5 shows a constant and progressive accumulation of oil at one location, suggesting that the stall-cell is immediately localized in its precise location with no-large spatial fluctuations. The abundance of oil in the stall-cell is conveyed from the recirculation region created by the buckling of the separation front. It can be further noted that a consistent modification of the oil path-lines from their straight path is seen upstream separation, much before the onset of the stall-cell pattern.

\subsection{Stereoscopic PIV analysis}

\subsubsection{Experimental setup}

Stereoscopic PIV measurements have been measured at several locations along the span-wise direction of the NACA64-418 wing. The averaged velocity fields have been combined in the span-wise direction to form a volume of data. Three velocity volumes have been created for angles of attack of $9^{\circ}-11^{\circ}-15^{\circ}$ at a Reynolds number of $R e=10^{6}$ by combining planes acquired at a minimum distance of $5 \mathrm{~mm}$ in the span-wise direction. Seeding particles from SAFEX-Long-Lasting-Mix are generated by a SAFEX fog machine able to provide droplets with a median diameter of $\approx 1 \mu \mathrm{m}$. The tracer droplets have been injected downstream the model, in order to determine a uniform and homogeneous concentration at the test section after flow recirculation in the closed circuit. Laser light provided by a Quantel CFR200 Nd:Yag laser with $200 \mathrm{~mJ}$ pulse $^{-1}$ has 


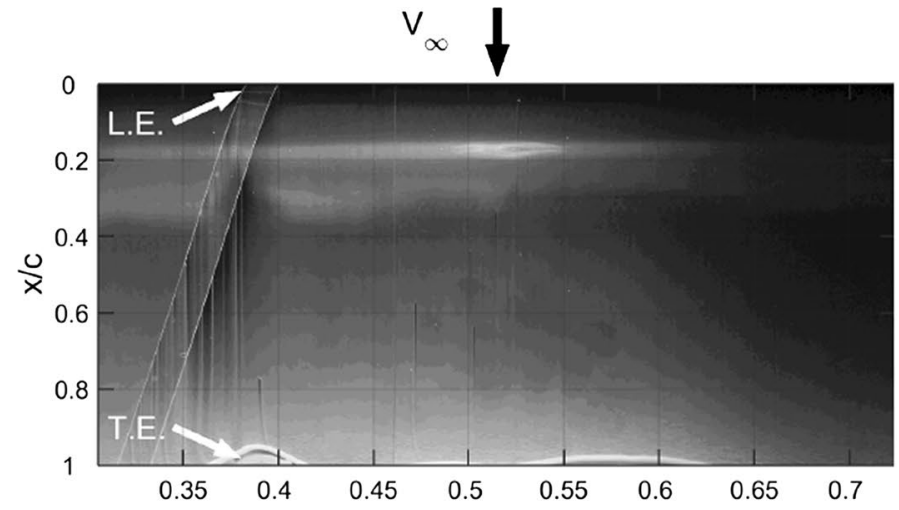

(a)

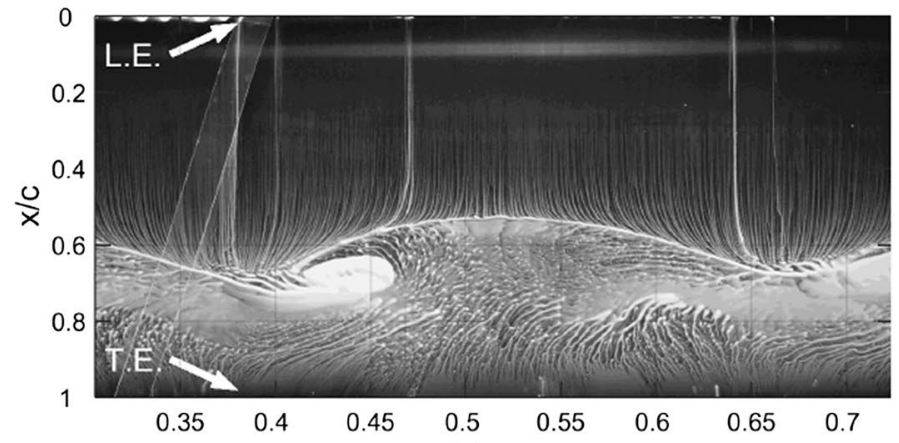

(c)

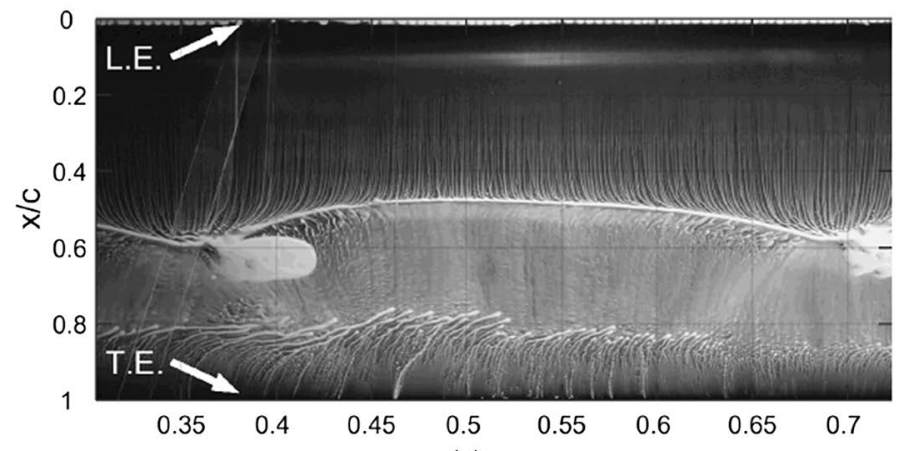

(e)

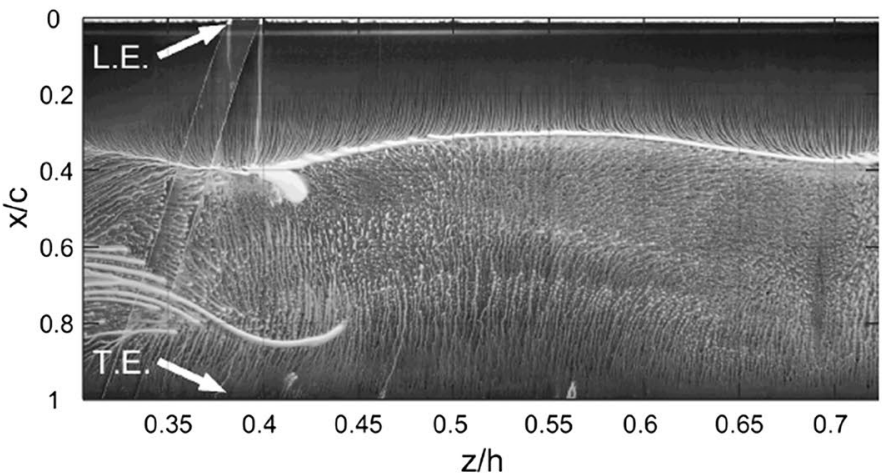

(g)

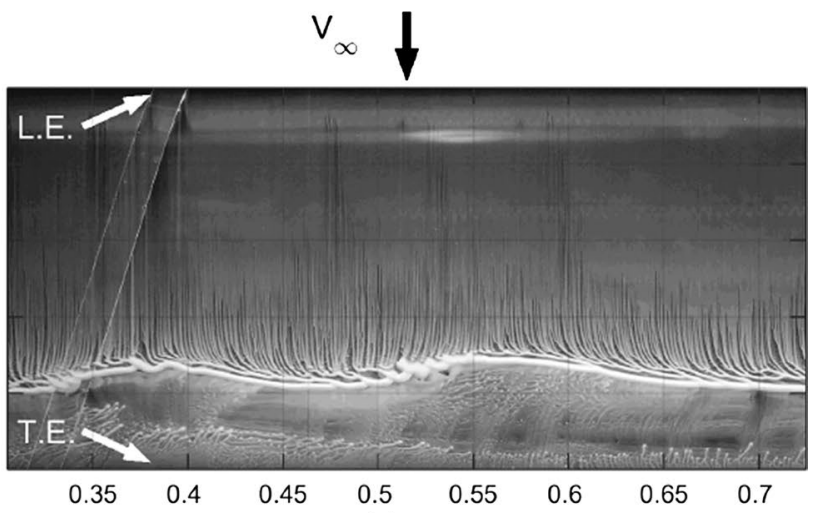

(b)

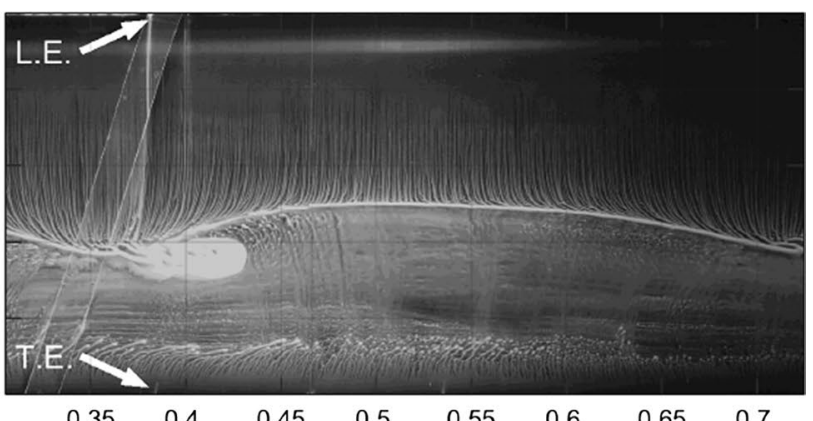

(d)
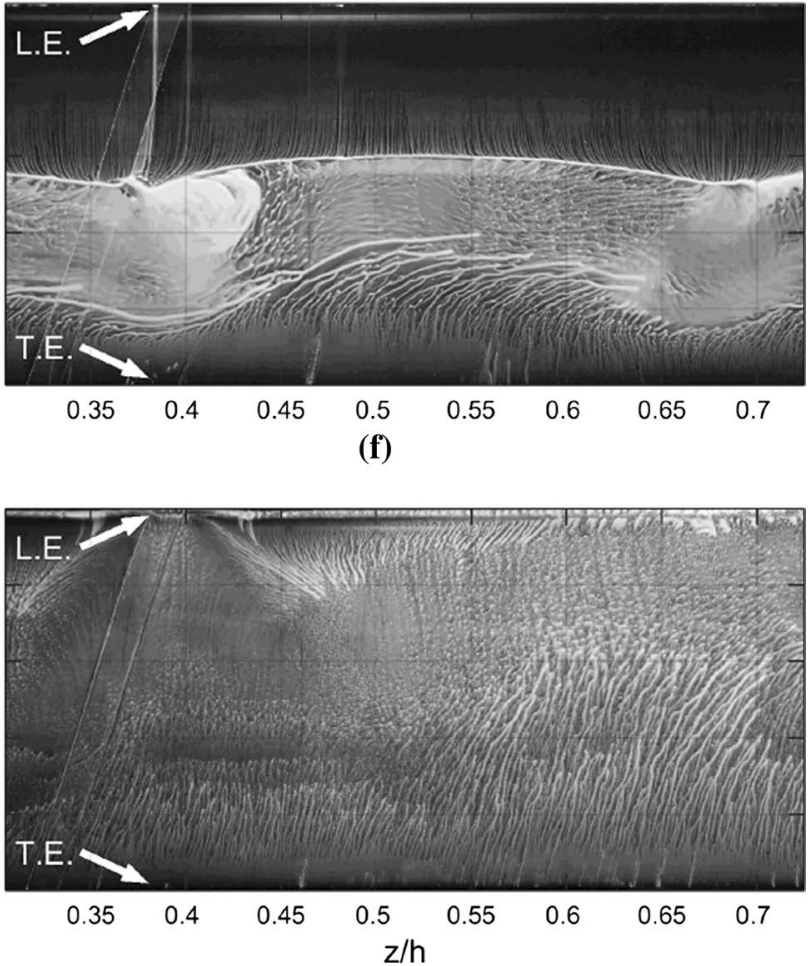

(h)
Fig. 4 Oil-flow visualizations of stall-cells in a NACA64-418 wing at $R e=10^{6}$. Coordinates normalized with the airfoil chord of $25 \mathrm{~cm}$ and the airfoil span $s=h$ of $1.25 \mathrm{~m}$. Results corrected by polyno- mial mapping into the plane $c \times s . \mathbf{a} \alpha=7^{\circ}, \mathbf{b} \alpha=9^{\circ}, \mathbf{c} \alpha=11^{\circ}, \mathbf{d}$ $\alpha=12^{\circ}, \mathrm{b} \alpha=13^{\circ}, \mathbf{f} \alpha=15^{\circ}, \mathbf{g} \alpha=18^{\circ}, \mathbf{h} \alpha=20^{\circ}$ 

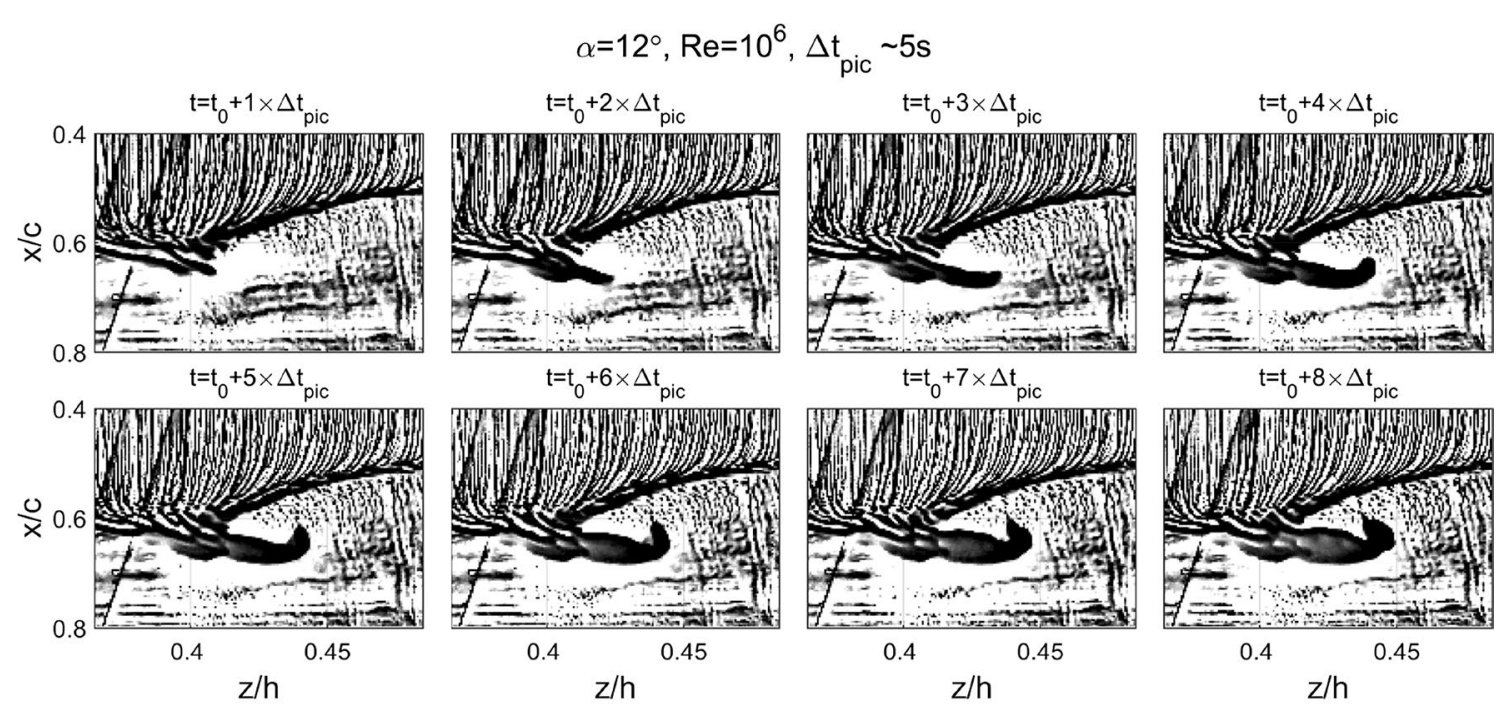

$\mathrm{t}=\mathrm{t}_{0}+7 \times \Delta \mathrm{t}_{\text {pic }}$
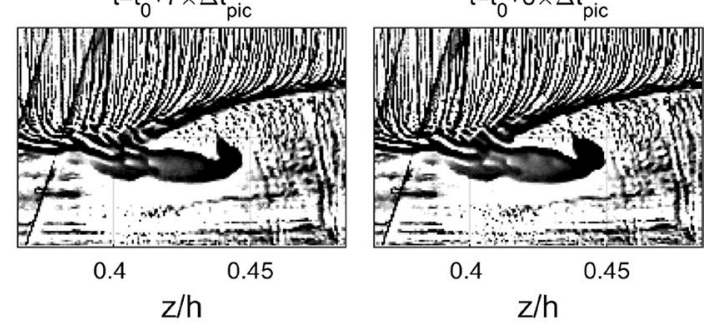

$$
\alpha=12^{\circ}, \operatorname{Re}=10^{6}, \Delta \mathrm{t}_{\text {pic }} \sim 5 \mathrm{~s}
$$
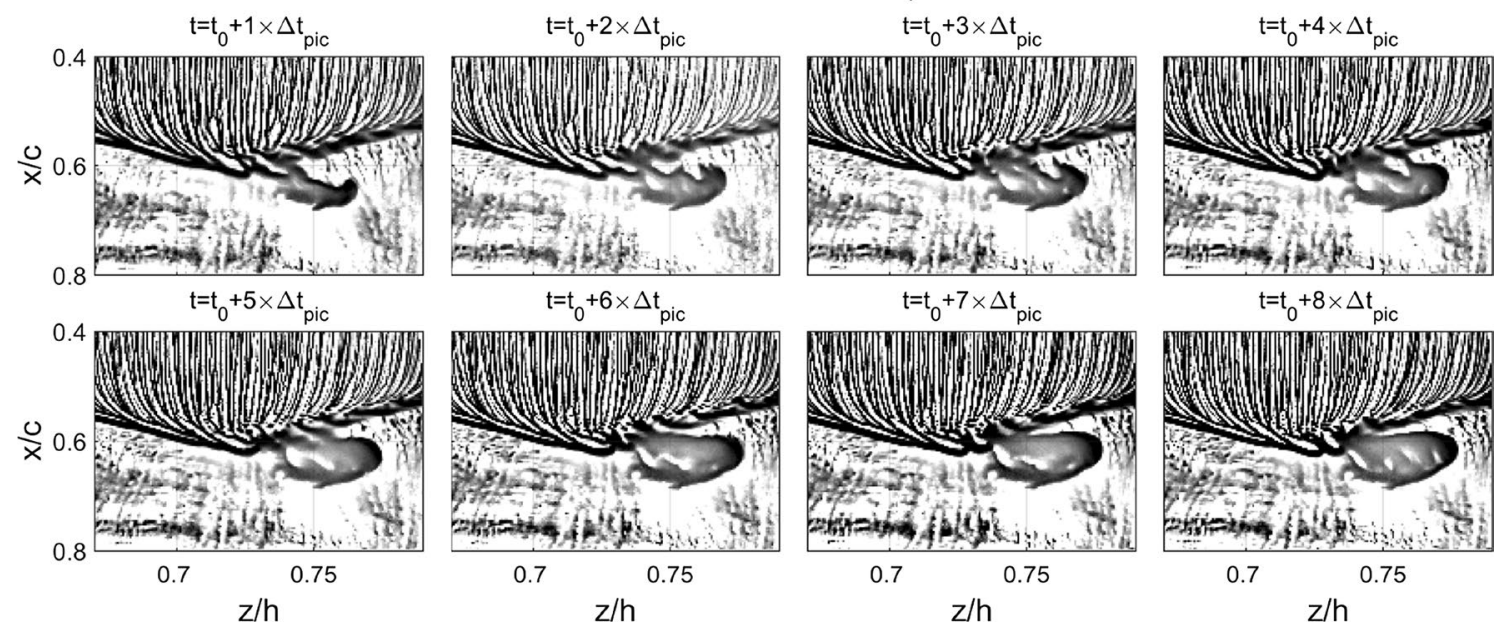

Fig. 5 Oil-flow visualization obtained by consecutive recording with about 5-s time delay. First and second rows correspond to the location of two consecutive stall-cells on the airfoil flow at $R e=10^{6}$ with $12^{\circ}$ angle of attack. Locations corresponding to Fig. 4

been conveyed through laser optics to form a laser sheet of about $35 \mathrm{~cm}$ width approximately $2 \mathrm{~mm}$ thick at the field of view (FOV) location. The flow is imaged by two CCD LaVision Imager Pro LX cameras with a sensor resolution of $4872 \times 3248 \mathrm{px}^{2}$ and a pixel pitch of $7.4 \mu \mathrm{m} / \mathrm{px}$. The two cameras are mounted with a relative angle of $37^{\circ}$, respectively, at about $10^{\circ}$ forward scatter. Two Nikon-Nikkor lenses of $f=180 \mathrm{~mm}$ focal length and aperture $f \# 5.6$ are mounted on the CCD cameras. At a distance of 1100 $\mathrm{mm}$, the cameras are imaging a field of view of about $30 \times 20 \mathrm{~cm}^{2}$ with a camera digital resolution of $10.1 \mathrm{px} /$ $\mathrm{mm}$ obtained from the final stereoscopic mapping of the two cameras. With the current magnification factor of 0.11 and the current aperture, the image particle size on the camera sensor of $1.3 \mathrm{px}$ (Westerweel 1997) allows mitigating the peak-locking problem. A histogram of the raw particle displacement is carried out to verify the absence of such a bias on the velocity fields. Image acquisition, processing and post-processing have been carried out by the LaVision DaVis 8.1.5 software. For each angle of attack and spanwise location, 150 images have been acquired and further processed by a multi-pass correlation algorithm, with a final window size of $16 \times 16 \mathrm{px}^{2}$ and $50 \%$ overlap, giving a final resolution of $1 \mathrm{~mm}$ and a vector spacing of 0.5 $\mathrm{mm}$. A schematic of the setup is presented in Fig. 6. The employed finite spatial resolution of the resulting velocity fields may limit the capture of flow structures. With the applied multi-pass cross-correlation algorithm, flow structures with size larger than 1.7 times the window size are measured with less than $5 \%$ modulation (Schrijer and Scarano 2008). Having a window size of $1 \times 1 \mathrm{~mm}^{2}$, the magnitude of flow structures down to $1.7 \mathrm{~mm}$ can thus be 
Fig. 6 Top view of the stereoscopic PIV apparatus. In the drawing: airfoil NACA64-418 in the test section, $\mathrm{C} 1$ and $\mathrm{C} 2$ cameras, laser illumination and seeding generator

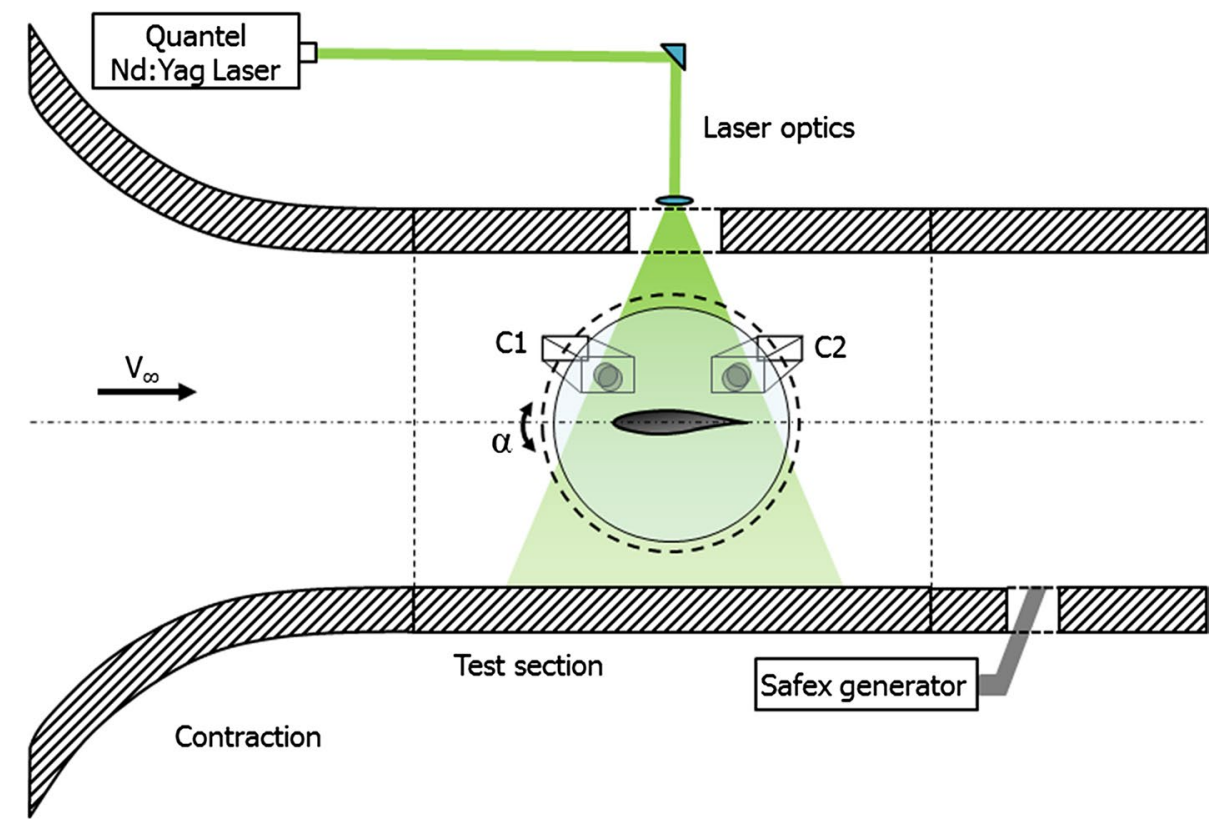

measured within $95 \%$ accuracy. An iterative self-calibration procedure was applied to further improve the fitting of the captured planes from the initial location-based calibration, which is based on a known three-dimensional target. The application of the two calibration procedures helps in reducing effects due to lens distortion. A final polynomial fitting used for the mapping of the images is implemented within DaVis and iterated on the raw images, yielding a disparity vector of less than $0.08 \mathrm{px}$ after self-calibration, considered satisfactory for stereoscopic cross-correlation (Raffel et al. 2007). The random errors on the averaged fields have been found to vary from less than $0.121 \mathrm{~m} \mathrm{~s}^{-1}$ $\left(0.2 \%\right.$ of the free-stream value at $\left.R e=10^{6}\right)$ to $0.81 \mathrm{~m} \mathrm{~s}^{-1}$ ( $1.5 \%$ of the free-stream value at $R e=10^{6}$ ) in the boundary-layer region. The method used to obtain this numbers has been based on the work of Wieneke (2015). Errors on the root-mean-square values have been found to be rather small $0.21 \mathrm{~m} \mathrm{~s}^{-1}$; however, due to the lower magnitude of such quantities the relative uncertainty due to random component still constitutes about $5-10 \%$ of the measured fluctuations in the boundary layer.

\subsubsection{Velocity fields in the separated region}

Oil-flow results have been discussed, showing the formation of a complex 3D flow pattern with the presence of periodic structures deforming the conventional flow topology of a lifting wing. In the present section, a detailed analysis of such flow properties is carried out. The final aim of this study is to quantify the effect of the stall-cells in the flow velocity and surface pressure. A detailed analysis of the flow velocity and pressure on both the wing surface and outer flow field would require multiple arrays of velocity and pressure transducers, spaced along the span direction with a resolution of less than $1 \mathrm{~cm}$. Typically, in industrial wind-tunnel experiments, airfoils are tested under the hypothesis of 2D flow, by extruding their profile into a wing with aspect-ratio larger than 4 . The pressure distribution is thus obtained from a single series of pressure taps inclined with respect to the mid-span line to ensure no interference between two consecutive sensors. In the present study, stereoscopic PIV has been employed to measure the airfoil flow velocity in several planes normal to the wing span. The flow pressure is then obtained by integrating the flow pressure gradient, obtained from the NavierStokes momentum equation with the PIV velocity as input, in a similar effort as in the work of van Oudheusden et al. (2007). Results have been compared to the ones of pressure taps in the wing, slanted at an angle of about $15^{\circ}$ in order to avoid flow interference. Results pertaining to different steady angles of attack are presented. Cameras and laser have been installed on a traversing system with $0.2 \mathrm{~mm}$ precision, employed for the acquisition of the stereoscopic PIV measurements in planes normal to the span-wise direction. The traversing system allows minimizing the amount of multiple calibration procedures, always maintaining the same viewing conditions for all the measured planes. The spacing between different measurement planes in the spanwise direction has been coherently chosen with the stall-cell periodicity, following the oil-flow results from Fig. 4. For the tested angles of attack, a minimum span range of $10 \mathrm{~cm}$ and a maximum of $25 \mathrm{~cm}$ has been measured, corresponding to minimum and maximum spacing between consecutive measurements in of 0.2 and $2 \mathrm{~cm}$. In Fig. 7 contours of 


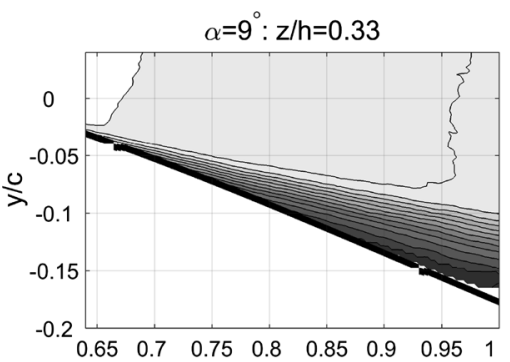

$\alpha=9^{\circ}: \mathrm{z} / \mathrm{h}=0.33$

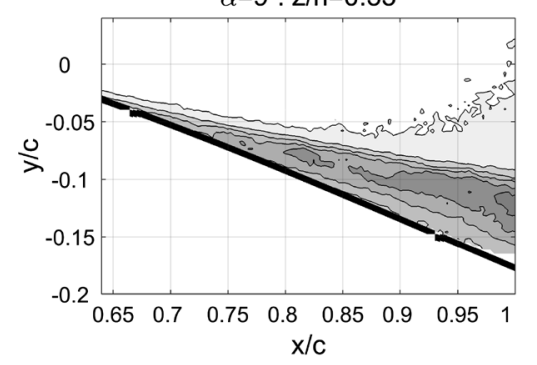

$\alpha=15^{\circ}: \mathrm{z} / \mathrm{h}=0.42$

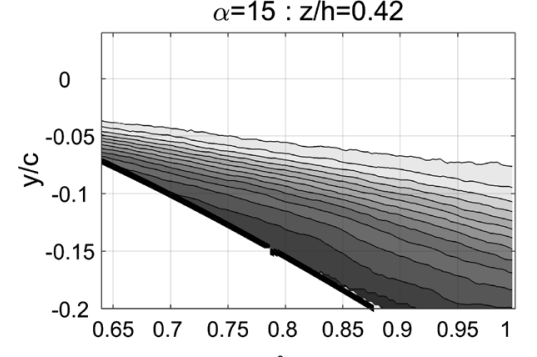

$\alpha=15^{\circ}: \mathrm{z} / \mathrm{h}=0.42$

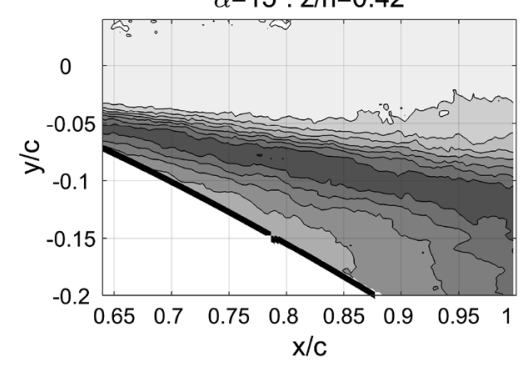

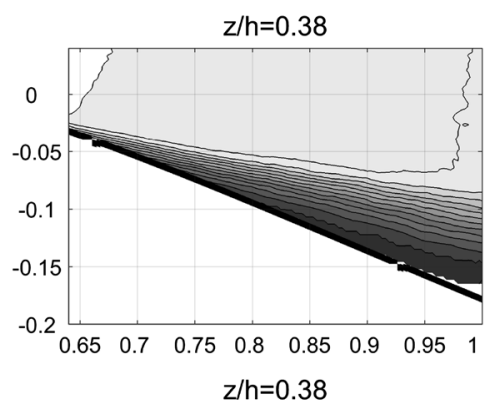
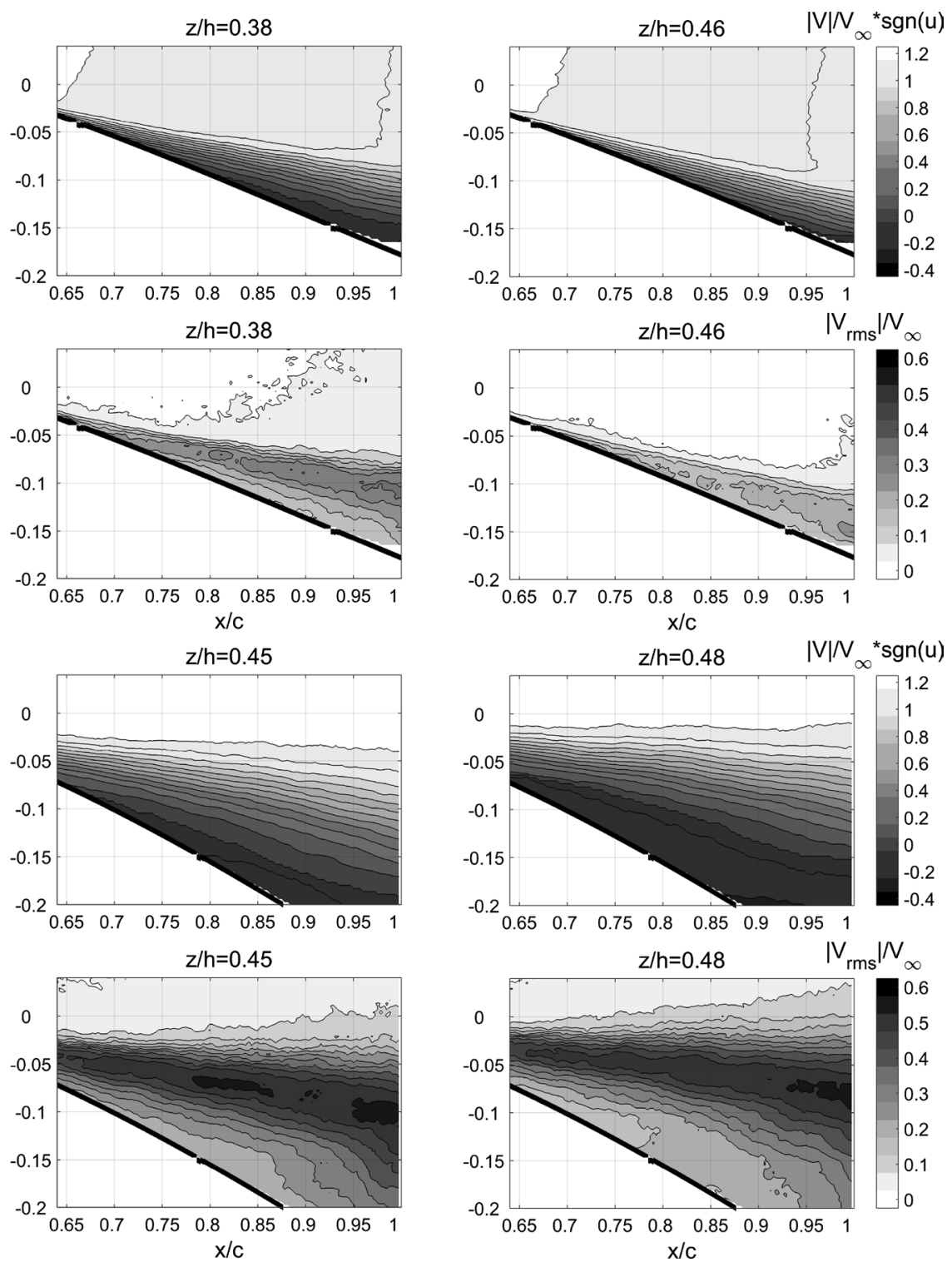

Fig. 7 Velocity magnitude and rms from stereoscopic PIV velocity fields acquired at different span-wise locations on the NACA64-418 wing. Rows of contours are organized per angle of attack: $9^{\circ}-15^{\circ}$. Results pertain to free boundary-layer transition at $R e=10^{6}$

normalized flow-velocity magnitude $|V| / V_{\infty} \times \operatorname{sgn}(u)$ are presented, where $|V|=\sqrt{u^{2}+v^{2}+w^{2}}$ and $\operatorname{sgn}(u)=u /|u|$ for $u \neq 0 \mathrm{~m} \mathrm{~s}^{-1}$ and $\operatorname{sgn}(u)=0$ for $u=0 \mathrm{~m} \mathrm{~s}^{-1}$. The flow fields pertaining to the most downstream region of the flow, respectively, at $9^{\circ}-15^{\circ}$ show the pressure recovery region developing from location $x / c=0.65$. Within the in-plane resolution of $1 \mathrm{~mm}$, which includes the moderate effect of reflections mainly affecting the region at the leading edge, a really small recirculation zone is appreciated at $11^{\circ}$ and $15^{\circ}$. The region of interest in the contours of Fig. 7 focuses on the location of the stall-cell formation, i.e., the most downstream location where flow separation occurs. The contours show a periodic non-uniformity along the span which develops in a modulation of the shear-layer thickness. The contours of Fig. 7 show an increase of velocity fluctuations along with the amplification of the shear layer.

Concurrently with the change in the shear-layer position and thickness along the span-wise direction, an increase of the velocity fluctuations is measured. However, this does not correspond to a net increase of the velocity fluctuations inside the separated region. This is also confirmed by previous studies (Manolesos et al. 2014), where higher values of flow fluctuations are measured at the stall-cell shear layer instead of at the trailing edge location. The reason for this seems to be ascribed to a low-frequency oscillatory motion of the stall-cells with higher amplitude than the conventional wake shedding determined at the trailing edge of such an airfoil. Once decomposing the flow fluctuations 
into single velocity components, it can be seen in Fig. 8 that vertical and stream-wise fluctuations are dominant with respect to the out-of-plane components. However, the lower measured out-of-plane fluctuations might be a result of the stability of such structures in the span-wise direction, which might be justified by the relatively higher wing aspect-ratio and the higher Reynolds number.

In Figs. 9 and 10, contours of root-mean-square fluctuations are shown as velocity magnitude decomposed along the stream-wise, vertical and span-wise directions. The magnitude of the fluctuations can be directly compared to the results in Fig. 4, where at the stream-wise location $x / c=0.9$, and in correspondence of span-wise locations of $z / c=0.41,0.55,0.6$, the stall-cells are formed. In correspondence of the stall-cell locations, higher fluctuations in the separated flow are measured. The particular shape of the high rms region follows the periodicity and the size of the stall cells, almost doubling from $9^{\circ}$ to $11^{\circ}$. Once decomposed into their Cartesian components in Fig. 10, the major contribution to the flow fluctuations is given by the vertical one. This is coherent with a flapping motion of the shear layer associated with the determination of the vortical structures aligned with the stream-wise direction, confirmed by previous literature works. More moderate is the span-wise activity with respect to the stream-wise and vertical one. This is confirmed once again in the manuscript by the results of Fig. 10.

A characteristic length can be calculated from the velocity contours by estimating the variation of the shear-layer thickness per span location. At $9^{\circ}$ and $11^{\circ}$ angle of attack, the oil-flow visualization showed a coherent bucking of about $\Delta z / h=0.1$ coherently with the value calculated at the same span-wise locations of Fig. 7. More complex is the analysis of the flow field at $15^{\circ}$ angle of attack, where the span-wise dislocation of the stall-cell extends further outside the flow field measured by stereoscopic PIV. Although the PIV resolution does not allow to resolve the small stall-cell formation in detail, traces of the trailing vorticity can be seen in Fig. 11 for $9^{\circ}$. Two main footprints in both the shear layer of the separated region and in the trailing vorticity from the stall-cell counter-rotating vortexpairs can be seen when plotting the vorticity $\omega_{x}$ component. The development of the vortical structures from the stallcells deforms the vorticity associated with the separated region. The shear layer, besides a main rotation in the $z$ direction (cfr. the high vorticity region in $\omega_{z}$ ), deforms in $x$
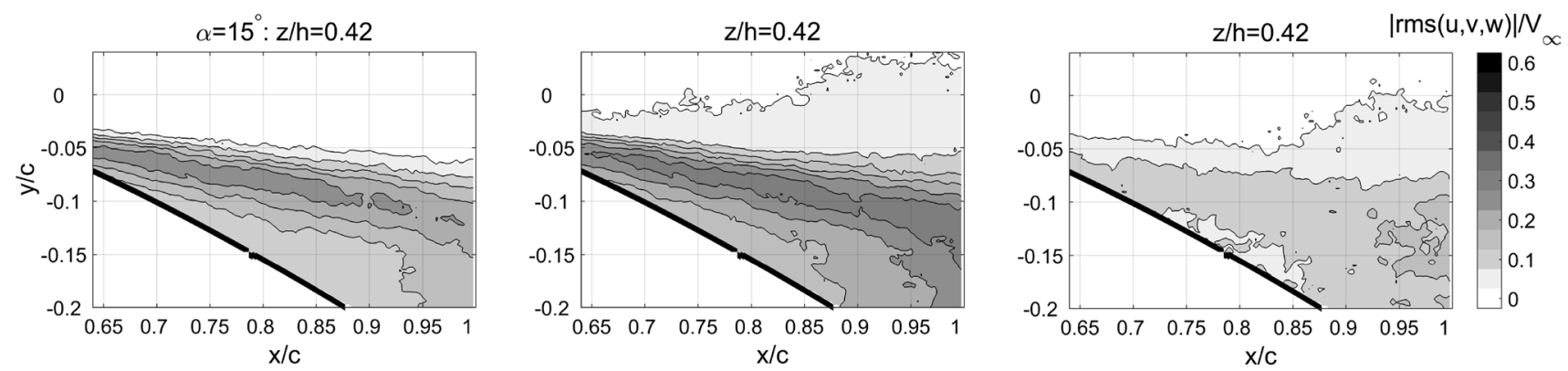

Fig. 8 Absolute rms velocity component in the stream-wise, vertical and out-of-plane directions. NACA64-418 at $15^{\circ}$ and $R e=10^{6}$
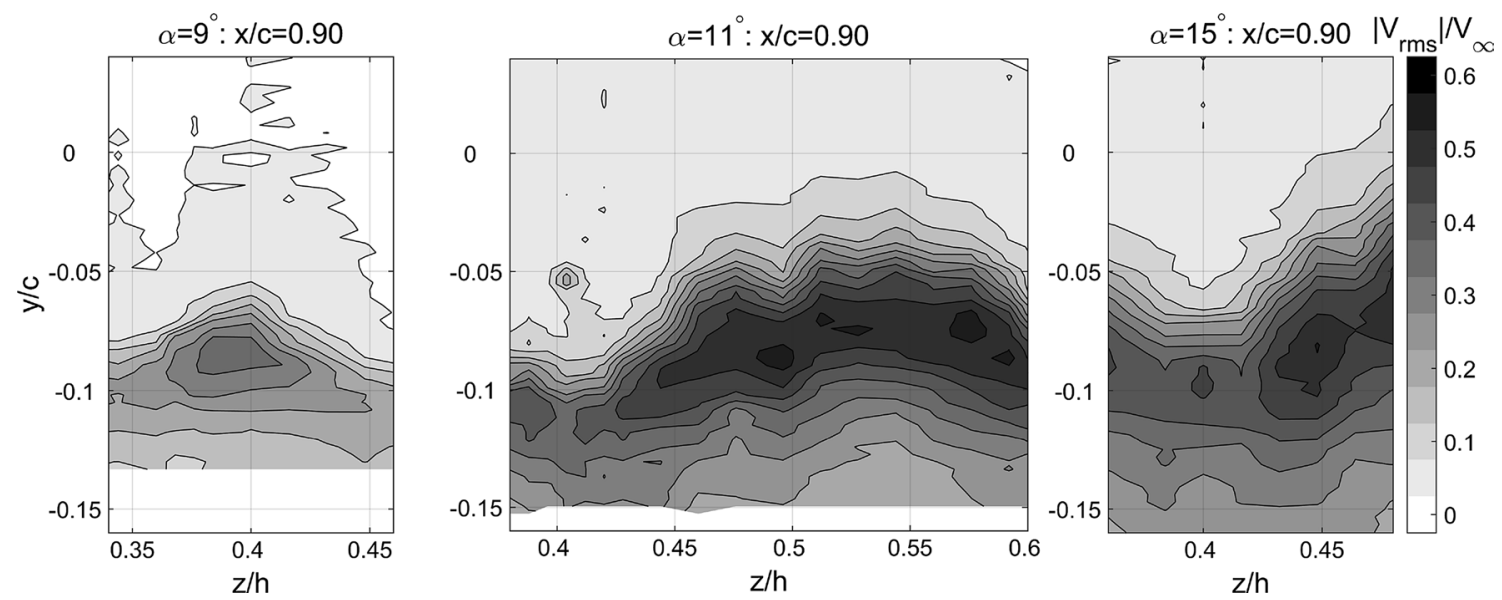

Fig. 9 Contours of magnitude of root-mean-square fluctuations in the span-wise direction. NACA64-418 at $9^{\circ}, 11^{\circ}, 15^{\circ}$ and $R e=10^{6}$ 
Fig. 10 Contours of root-meansquare fluctuations decomposed in stream-wise, vertical and span-wise contributions. NACA64-418 at $9^{\circ}, 11^{\circ}, 15^{\circ}$ and $R e=10^{6}$

Fig. 11 Contours of vorticity component along the streamwise, vertical and span-wise directions. NACA64-418 at $9^{\circ}$ angle of attack, $R e=10^{6}$
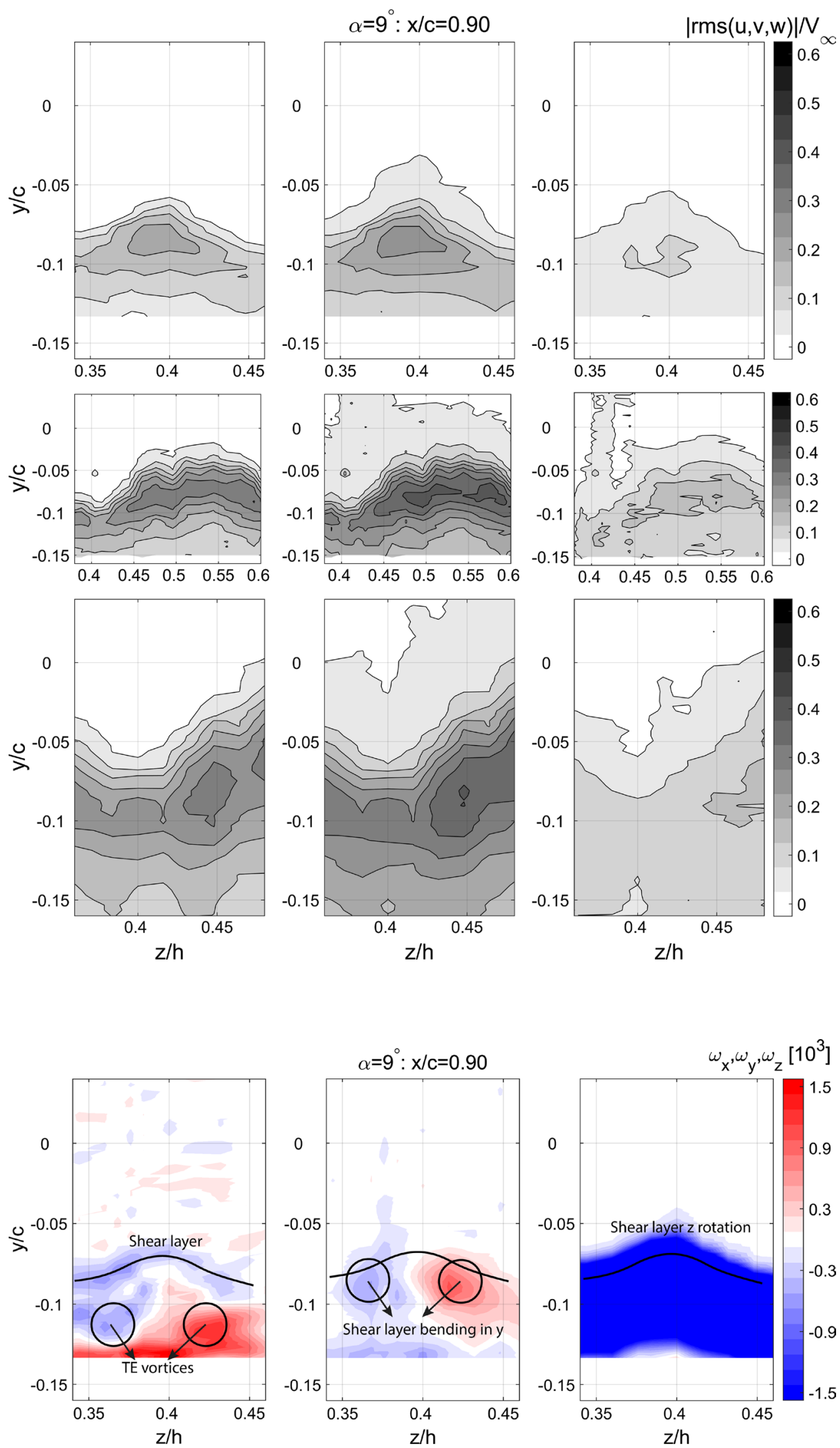


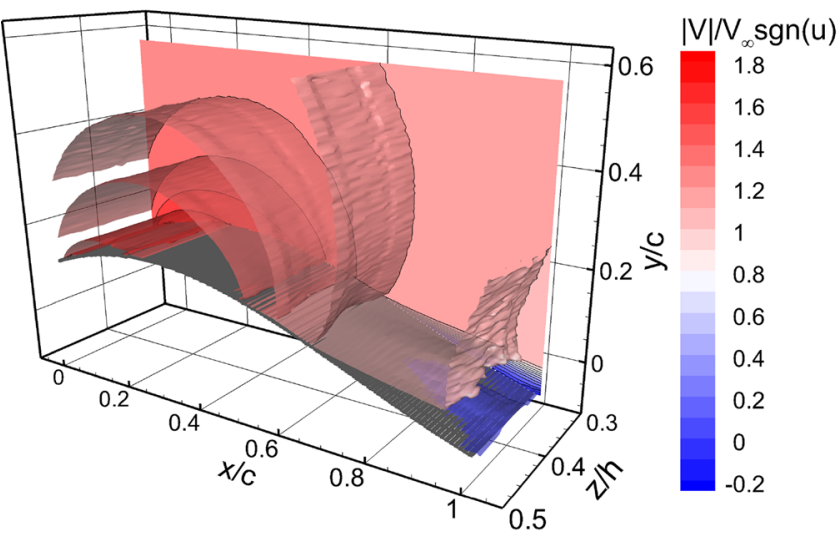

(a)

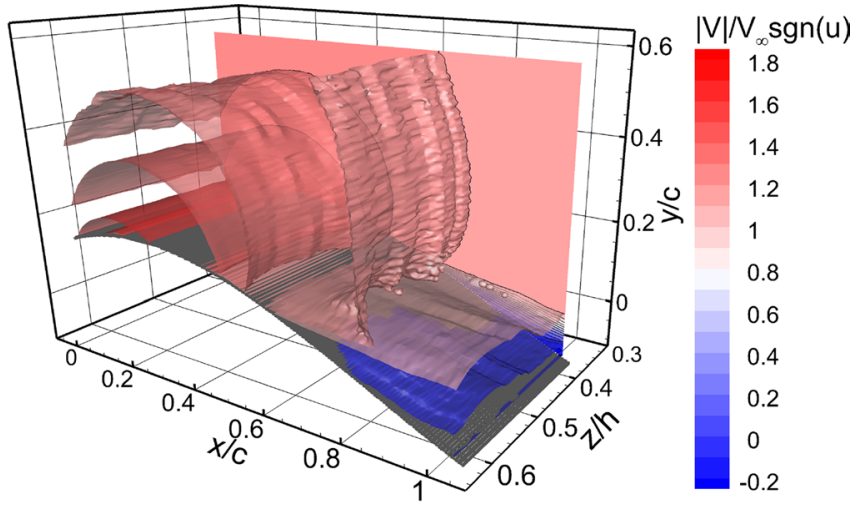

(b)

Fig. $123 \mathrm{D}$ normalized velocity contours for $9^{\circ}$ and $11^{\circ}$ angle of attack, $z / h$ axis expanded by a factor 2 for clarity, NACA64-418, $R e=10^{6}$. $\mathbf{a} \alpha=9^{\circ}, \mathbf{b} \beta=11^{\circ}$

and $y$ directions with subsequent positive and negative vorticity regions corresponding to the bending of the separation line seen in the schema of Fig. 3.

\subsubsection{D velocity representation of the wing flow}

The stall-cell pattern in the NACA64-418 wing determines an additional modification of the outer flow field, which is studied in this paragraph by combining the stereoscopic velocity data into a volumetric visualization in Fig. 12. In the visualization, two angles of attack are presented. The separated region follows the separation front as already indicated by the oil-flow visualization of Fig. 4 from $x / c=$ 0.8 to $x / c=0.4$ when increasing the angle of attack from $9^{\circ}$ to $11^{\circ}$. At the limit of the PIV resolution, the three-dimensional deformation of the separated front at the stall-cell location is not as visible as in the outer region of the wing flow. The 3D visualization for the different angles in Fig. 12 is normalized with the $u$ component, in the free-stream direction. Several surfaces are added at $|V| / V_{\infty} \times \operatorname{sgn}(u)$ to indicate the region of flow acceleration down to the separation at $|V| / V_{\infty} \times \operatorname{sgn}(u)=0$, visible at about $x / c=0.8$ for the different cases. The three-dimensionality of the separation shows a buckling of about $\Delta z / h=0.08$ slightly smaller than what already confirmed by Fig. 7 and by the oil-flow visualizations in Fig. 4. The three-dimensional pattern in the airfoil flow separation becomes more evident at higher angle of attack $\left(11^{\circ}\right)$, with the separation region deforming from a uniform front at about $\Delta z / h=0.2$. The presence of the three-dimensional change of the contour geometry is additionally evidenced in the most upstream iso-surfaces, as the ones taken at $|V| / V_{\infty} \times \operatorname{sgn}(u)>1.3$ deformed in correspondence of the mid-span location of the three-dimensional structure. It can be anticipated that the three-dimensionality of the separation front propagates to the flow at the suction side, as the contours at relatively higher velocity magnitude indicate. This demonstrates that, besides the fluctuating component previously discussed, the presence of the stall-cell pattern induces a net change in the mean pressure field on the wing surface. The present effect, whether it can be modeled as a relative change of the flow angle of attack in the span-wise direction or as a localized change in flow pressure, will be investigated in the section dedicated to the quantification of the change in loading with respect to the quasi-2D airfoil performance.

\section{Pressure distribution along the wing span}

In the present section, an attempt is made to quantify the span-wise variations of the load distribution of the wing. To the purpose, the surface pressure as obtained from integration of the experimental velocity is compared to the results obtained from direct measurements via pressure taps in the wing model. The time-averaged pressure gradient and the Laplacian of the pressure field have been first computed by employing the Navier-Stokes momentum in the Reynolds average form van Oudheusden et al. (2007) with the experimental velocities as input. Integration of the pressure gradient derived from the Navier-Stokes equations has been carried out by solving the Poisson equation using the 3D velocity information with both Neumann and Dirichlet (Bernoulli pressure) conditions in the boundaries of the domain. Details of the procedure can be found in van Oudheusden et al. (2007), with several applications in lowand high-speed aerodynamics (van Oudheusden 2013). The present methodology allows using the vector field statistics as input in a similar manner as in Ragni et al. (2012) to obtain the mean surface pressure. If the flow is stationary in the statistical sense, the scanning stereoscopic PIV setup 
still allows obtaining the mean pressure field, without the need of having time-resolved measurements. The procedure has already been found by the authors to have comparable accuracy to conventional pressure probes, especially when the flow accelerations are moderate (Ragni et al. 2014).

\subsection{Distributed pressure orifice results}

The pressure coefficient distributions in Fig. 13 are the results of consecutive measurements acquired via a scannivalve system with 52 pressure probes distributed along a line inclined of about $15^{\circ}$ with respect to the chord. The inclination with respect to the mid-span location is meant to avoid flow interference between two consecutive orifices in the measurements of the surface pressure. The surface pressure coefficients are obtained in red for the airfoil top surface and in black for the bottom one. The lines show the typical flow behavior for a laminar airfoil. The cambered shape determines an asymmetrical pressure distribution at $0^{\circ}$ angle of attack with the presence of a laminar separation bubble at the top surface, as shown from the abrupt change in curvature in the pressure coefficient at the suction side at about $x / c=0.5$. At positive pitch, a pressure coefficient peak on the suction side starts developing from $8^{\circ}$ angle of attack, reaching his maximum $c_{p}=-5.88$ at $20^{\circ}$ angle of attack. The NACA64-418 airfoil separation can

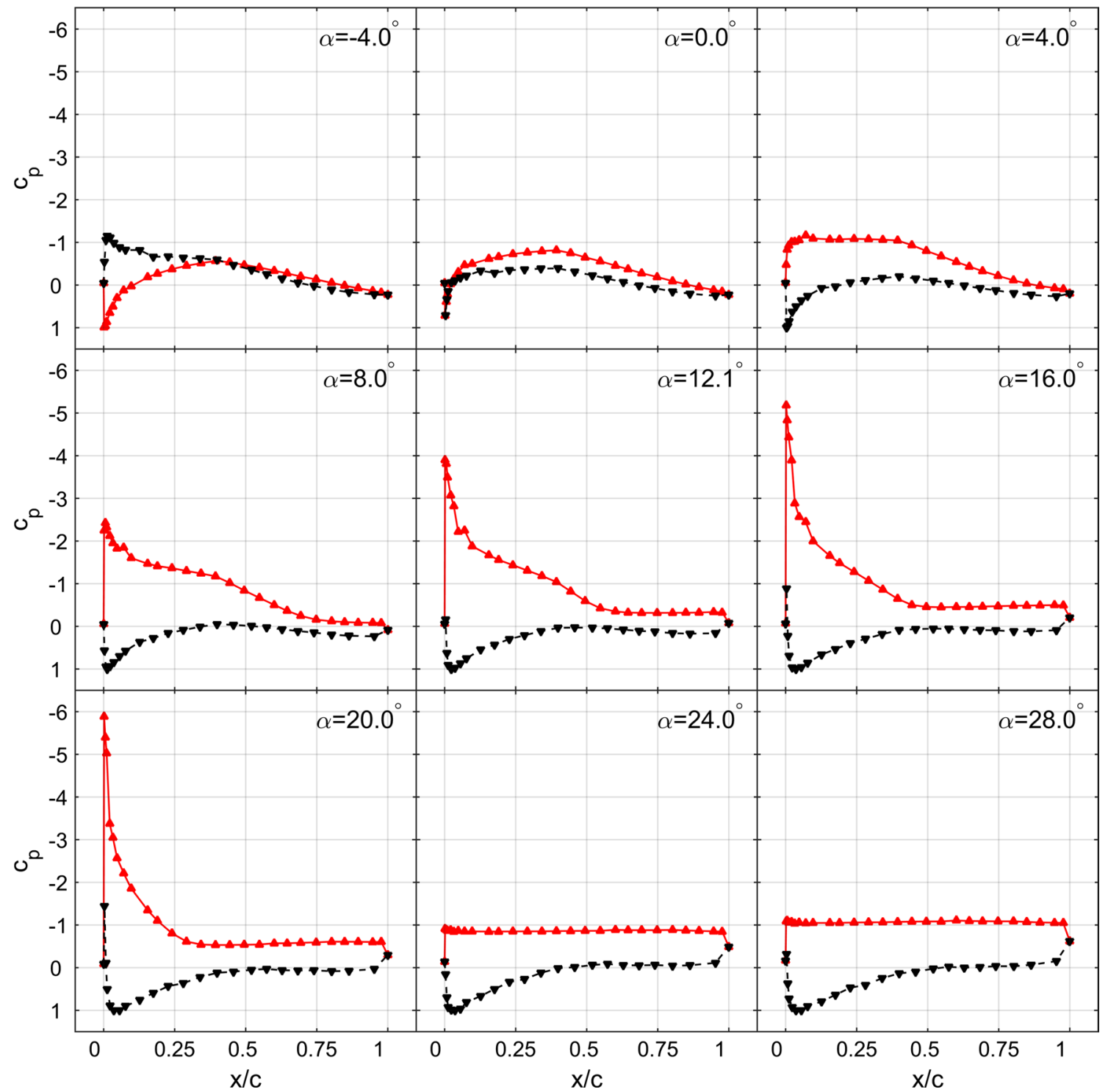

Fig. 13 Pressure coefficient distributions as obtained from 52 pressure taps distributed along the airfoil, at stream-wise locations indicated in Fig. 1; no interference ensured by inclination of the taps line along the span-wise direction of $15^{\circ}$. Red top surface pressure distri- bution, black bottom surface pressure distribution. Averaged results obtained from a scanni-valve system acquiring about 360 samples in $3 \mathrm{~min}$ 

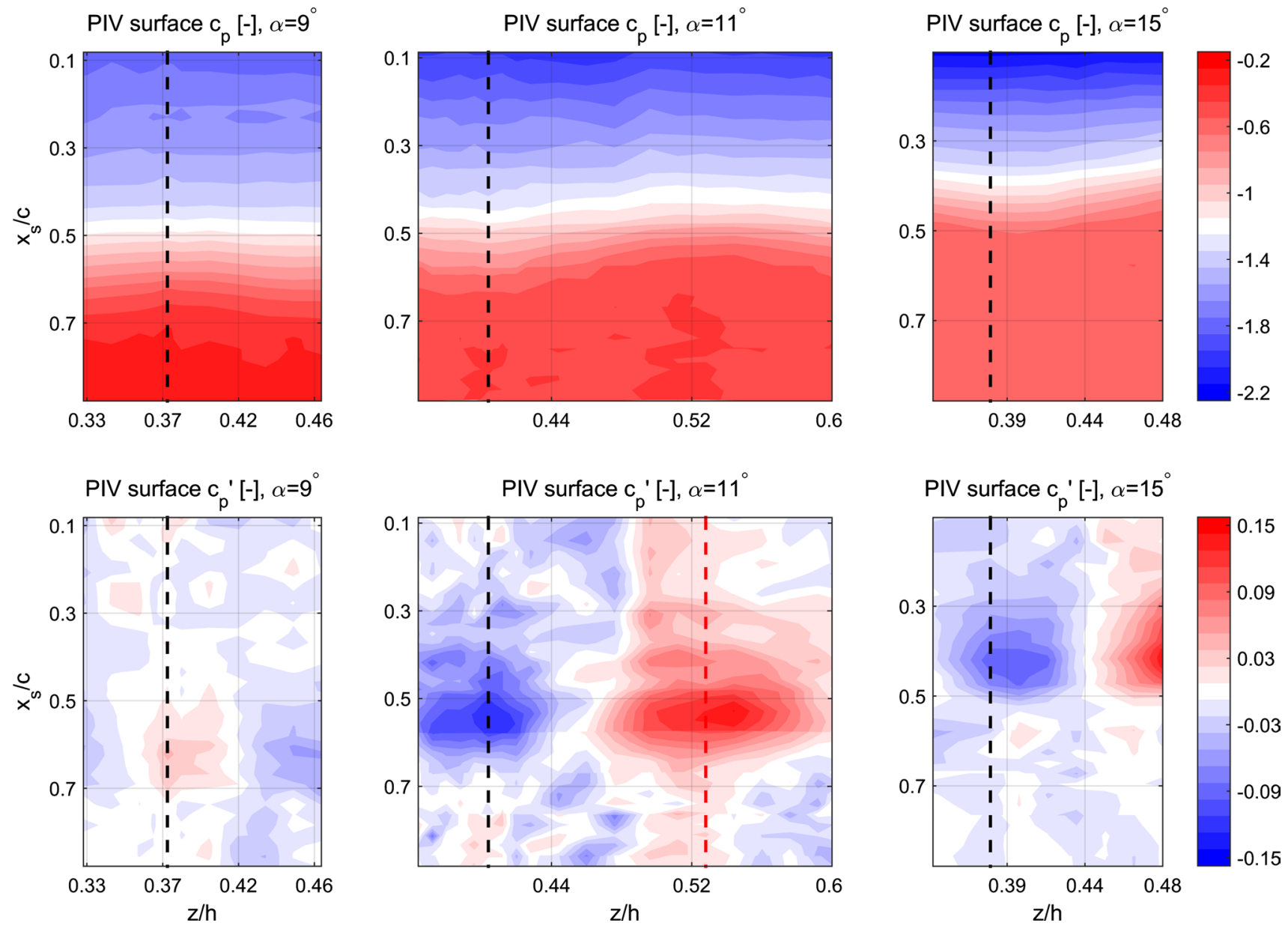

Fig. 14 Contours of surface pressure coefficient and spatial fluctuations as derived from PIV-based pressure evaluation on the suction side of the wing. Columns are organized per angle of attack. Data pertaining to the NACA64-418 wing, $9^{\circ}, 11^{\circ}, 15^{\circ}, \operatorname{Re}=10^{6}$

be already seen at $8^{\circ}$ pitch on the suction side. At the same angle, a change in curvature is also evident at about $x / c=$ 0.4 just before the incipient separation. It has to be noted that this change in curvature on the suction side is persistent till $20^{\circ}$, angle at which the flow fully separates on the top surface. Although exactly in the range of the stall-cells development, it is difficult to ascribe the particular change in performance to the stall-cell pattern, especially when considering the chord-wise distribution of the pressure orifices slanted with respect to the middle span. It is a fact that when comparing $4^{\circ}, 8^{\circ}$ and $20^{\circ}$ at chord locations of $x / c$ between 0.10 and 0.50 , a different mechanism of flow separation is seen. The separation front moves upstream from the trailing edge till $24^{\circ}$, first point where the flow is fully detached on the top surface.

\subsection{Span-wise pressure coefficient distributions}

In the present section, the single distribution of the mean flow pressure as obtained from the pressure taps has been compared to the surface data obtained from the PIV velocity fields in Fig. 14. The data shown in Figs. 7 and 12 are used as input in the pressure integration methodology from stereoscopic PIV, in order to quantify the span-wise variation in the airfoil loading with respect to the mean one. The comparison is mainly focused in the pressure recovery region, where accelerations are moderate and the effect of the three-dimensional stall-cell structure is more visible. In this region, the uncertainty on the pressure coefficient derived from PIV is comparable to the one of the pressure orifices, and the technique is able to discern pressure coefficient variations with an uncertainty of about 0.02 . Figure 14 shows the pressure data at the surface as derived from PIV for the tested angles of attack. The change in pressure due to the presence of the stall-cell on the mean field is a fraction of the overall pressure distribution on the airfoil wing. Therefore, in the second row of Fig. 14 the span-wise average component of the pressure coefficient, that is the average along the span direction of the pressure coefficient at the same chord-wise locations per PIV plane, 

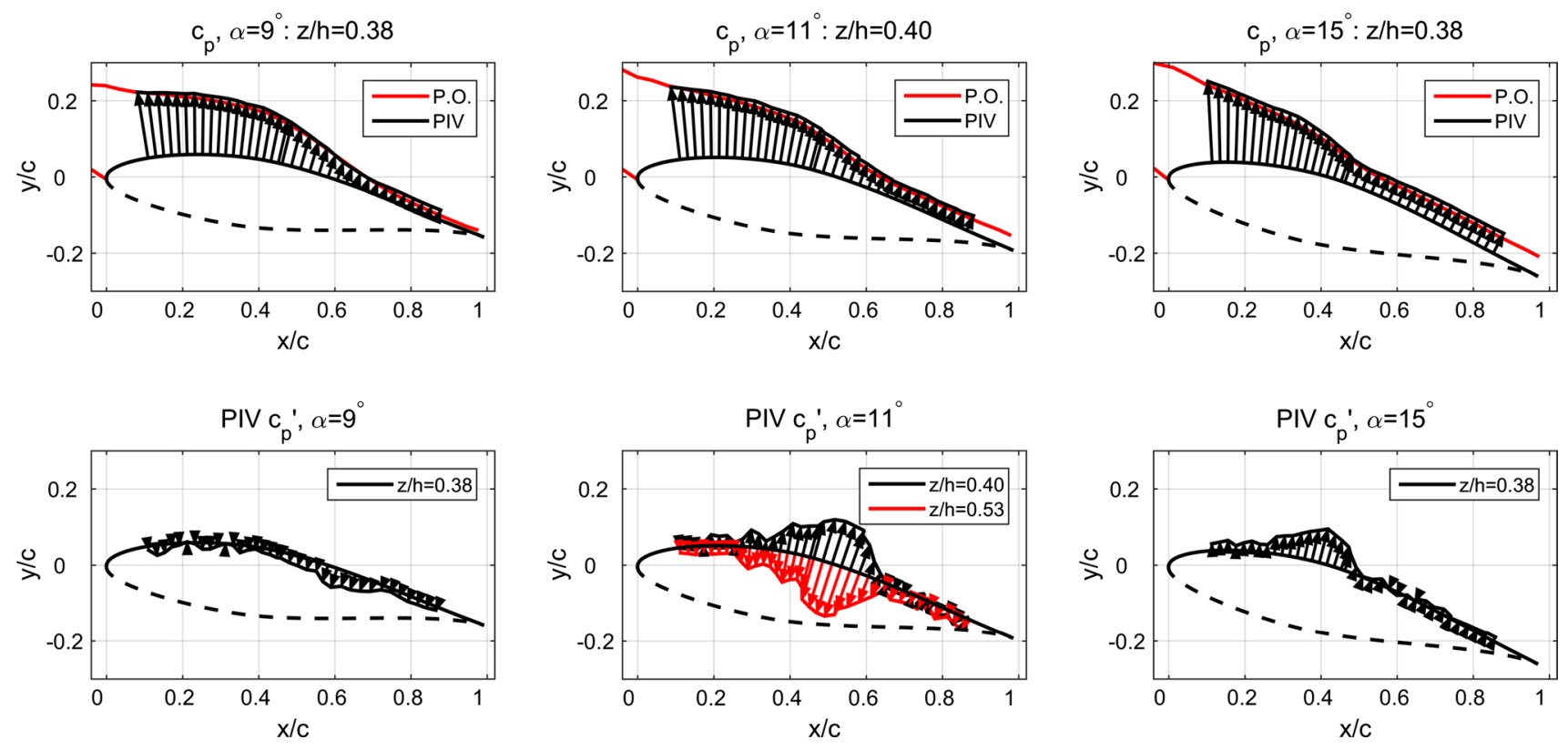

Fig. 15 Surface pressure coefficient and spatial fluctuations as derived from PIV-based pressure evaluation on the suction side of the wing. Lines and arrow-plots obtained for three angles of attack and extracted at the dash-dot locations of Fig. 14. Data pertaining to the NACA64-418 wing, $9^{\circ}, 11^{\circ}, 15^{\circ}, R e=10^{6}$

Table 1 Integration of $c_{p}^{\prime}$ variations of Fig. 14 into Newton force in percentage of total wing lift/drag

\begin{tabular}{lllllc}
\hline$\alpha^{\circ}$ & Lift N & Drag N & $\begin{array}{l}\text { Mean F } \\
(\% \text { Lift })\end{array}$ & $\begin{array}{l}\text { Rms. F } \\
(\% \text { Lift })\end{array}$ & $\begin{array}{l}\text { Rms. F } \\
(\% \text { Drag })\end{array}$ \\
\hline 9 & 752.5 & 19.2 & 0.1 & 1.1 & 45.5 \\
11 & 795.9 & 33.5 & 0.9 & 6.4 & 127.5 \\
15 & 824.5 & 71.2 & 0.1 & 2.9 & 27.7 \\
\hline
\end{tabular}

Estimation carried out with distribution of the pressure side as from Fig. 13. As expected, the mean force on the wing ascribed to spatial pressure coefficient variations is almost negligible compared to the spatial rms values

in pressure coefficient is given by a lower angle of attack than the one of the maximum pressure coefficient, precisely the one where the corresponding oil-flow measurements present a sharper recirculation zone. In this respect, in Table 1 an attempt is made to convert the surface spanwise change in the pressure coefficient into fluid force. Integration of the pressure coefficient with normalization per measured area, an overall rms change of lift coefficient of about $\Delta c_{l}=1 \% ; 6 \% ; 3 \%$ is computed with respect to the lift of the airfoil at the prescribed angles of $9^{\circ}, 11^{\circ}$ and $15^{\circ}$. Although this corresponds to a negligible change with respect to the total lift of the wing (quantified by integrating positive and negative changes into the mean force on the wing), local non-uniformities are rather larger and comparable to the drag values. It has to be reminded that this effect is already present in the mean pressure field, tion. It can also be noted that the highest span-wise change 
on which the fluctuating component due to the oscillatory motion of the stall-cells has to be superimposed.

\section{Conclusions}

The effect of stall-cells on the mean flow velocities and pressure of a NACA64-418 has been investigated. Flow visualization at Reynolds $R e=10^{6}$ showed the presence of a pattern of stall-cells which develops from $9^{\circ}$ up to $20^{\circ}$ angle of attack. The size and the shape of such structures have been found in agreement with previous literature, with a stall-cell inner-size growing up to $0.2 c$. Footprints of the presence of a small leading-edge separation bubble have been measured in pressure orifices data. However, its effect does not seem to influence the stall-cell development until the full separation at the suction side is reached. An investigation carried out by employing a multi-plane stereoscopic PIV setup showed the presence of a span-wise nonuniformity in the separation front of the wing, with maxima of root-mean-square velocity fluctuations still localized in correspondence of the shear-layer profile. Analysis of the single velocity and vorticity components show vortical features aligned with the stream-wise direction, deforming the shear-layer profile in both vertical and span-wise directions. This is also confirmed by the stronger contribution of the vertical and stream-wise fluctuations when compared to the span-wise ones. This particular fact suggests that the shedding of the separation front is decoupled from its breaking, forming the stall-cells pattern. Stacking of the different stereoscopic velocity fields pertaining to different span-wise locations shows that the influence of the pattern is extended to outer regions upstream the wing separation, as well as determining a periodic change in the whole wing velocity and pressure field. Integration of the PIV velocity fields into pressure shows a net modulation effect in the spanwise direction which localized in a vast region between the maximum suction peak and the beginning of the separation front, with maximum variations of about 0.15 dictated by the strength of the vortical structures at the stall-cell location, and not by the local pressure peak of the wing. While this effect is clearly visible in the span-wise distribution of the surface pressure coefficient, the final effect on the pressure orifices is similar to a local change in the airfoil curvature. This effect is already measured on the mean pressure field, and it might have important repercussions on the flow separation zone, where the pressure fluctuations are mainly located. The pressure coefficient variations along the wing span mainly distribute along the pressure recovery zone of the airfoil profile. Integration of such distribution along the full span has been attempted, conveying maximum rms fluctuations with respect to the mean lift coefficient of about $2-6 \%$. Future work is dedicated to further characterize the time characteristics and the stability of the stall-cells in function of the pressure field regenerated along the wing.

Open Access This article is distributed under the terms of the Creative Commons Attribution 4.0 International License (http://creativecommons.org/licenses/by/4.0/), which permits unrestricted use, distribution, and reproduction in any medium, provided you give appropriate credit to the original author(s) and the source, provide a link to the Creative Commons license, and indicate if changes were made.

\section{References}

Bippes H, Smith FT, Brown SN (1987) Experimental investigation of topological structures in three-dimensional separated flow. Bound Layer Sep. Springer, Berlin

Boiko AV, Dovgal AV, Zanin BY, Kozlov VV (1996) Three-dimensional structure of separated flows on wings. Thermophys Aeromech 3(1):1-13

Braslow A, Knox E (1958) Simplified method for determination of critical height of distributed roughness particles for boundarylayer transition at Mach numbers from 0 to 5, Naca technical note

Broeren A, Bragg MA (2001) Spanwise variation of the unsteady stalling flowfields of two-dimensional airfoil models. AIAA J 39(9):1641-1651

Burton T, Sharpe D, Jenkins N, Bossanyi E (2001) Wind energy handbook. Wiley, New York

Carta FO (1975) Chordwise propagation of dynamic stall cells on an oscillating airfoil. AIAA Pap 25:1-9

Clancy LJ (1975) Aerodynamics. Pitman Publishing Limited, Long Acre

Crimi P, Reeves BL (1976) Analysis of leading-edge separation bubbles on airfoils. AIAA J 14(11):1548-1555

Crow SC (1970) Stability theory for a pair of trailing vortices. AIAA J 8(12):2172-2179

Disotell KJ, Gregory JW (2015) Time-resolved measurement of cellular separation of a stalling airfoil. In: Proceedings of the AIAA SciTech 5-9 January, AIAA, Kissimmee, Florida

Elimelech Y, Arieli R, Iosilevskii G (2012) The three-dimensional transition stages over the NACA-0009 airfoil at Reynolds numbers of several ten thousand. Phys Fluids 24:024104. doi:10.1063/1.3682377

Gregory N, Quincey V, O'Reilly C, Hall D (1971) Progress report on observations of three-dimensional flow patterns obtained during stall development on aerofoils, and on the problem of measuring two-dimensional characteristics, British a.r.c.c.p

Hu H, Zifeng Y (2008) An experimental study of the laminar flow separation on a low-Reynolds-number airfoil. J Fluids Eng 130:051101

Kozlov VV, Zverkov ID, Zanin BY, Dovgal AV, Rudyak VY, Bord EG, Kranchev DF (2006) Experimental and theoretical investigation of boundary layer perturbations on a low-aspect-ratio wing. Themophys Aeromech 13(4):507-514

Manolesos M, Papadakis G, Voutsinas S (2014) Experimental and computational analysis of stall cells on rectangular wings. J Wind Energy 17(6):939-955

Noca F, Shiels S, Jeon D (1999) A comparison of methods for evaluating time-dependent fluid dynamic forces on bodies, using only velocity fields and their derivatives. J Fluids Struct 13:551-578

Ottavio JD, Watson K, Cormey J, Komerath N (2008) Discrete structures in the radial flow over a rotor blade in dynamic stall. In: Proceedings of the 26th AIAA applied aerodynamics conference 18-21 August, AIAA, Honolulu, Hawaii 
Raffel M, Willert CE, Wereley ST, Kompenhans J (2007) Particle image velocimetry - a practical guide. Springer, Berlin

Ragni D, van Oudheusden BW, Scarano F (2012) 3D pressure imaging of an aircraft propeller blade-tip flow by phase-locked stereoscopic PIV. Exp Fluids 52(2):463-477

Ragni D, Ferreira CS, Correale G (2014) Experimental investigation of an optimized airfoil for vertical-axis wind turbines. J Wind Energy 18(9):1629-1643

Rodriguez D, Theofilis V (2010) On the birth of stall cells on airfoils. Theor Comput Fluid Dyn 25(105):1-4

Schewe G (2001) Reynolds-number effects in flow around more-orless bluff bodies. J Wind Eng Ind Aerodyn 89(14-15):1267-1289

Schrijer FFJ, Scarano F (2008) Effect of predictor-corrector filtering on the stability and spatial resolution of iterative PIV interrogation. Exp Fluid 45(5):927-941

Selig MS, Deters RW, Williamson GA (2011) Wind tunnel testing airfoils at low Reynolds numbers. In: Proceedings of the 49th aerospace sciences meeting 4-7 January, AIAA, Orlando, FL

Selig MS, Guglielmo JJ, Broeren AP, Gigure P (1995) Summary of low-speed airfoil data. SoarTech, Virginia Beach

Selle J (1999) Study on the effectiveness of turbulator tape on boundary-layer transition. Technical report, University of California at Davis

Taira K, Colonius T (2001) Three-dimensional flows around lowaspect-ratio flat-plate wings at low Reynolds numbers. J Fluid Mech 623:187-207 van Oudheusden BW, Scarano F, Roosenboom EWM, Casimiri EWF, Souverein LJ (2007) Evaluation of integral forces and pressure fields from planar velocimetry data for incompressible and compressible flows. Exp Fluids 43(2):153-162

van Oudheusden BW (2013) PIV-based pressure measurement. Meas Sci Technol 24(3):032001. doi:10.1088/0957-0233/24/3/032001

Weihs D, Katz J (1983) Cellular patterns in poststall flow over unswept wings. AIAA J 21(12): 1757-1759

Westerweel J (1997) Fundamentals of digital particle image velocimetry. Meas Sci Technol 8:1379-1392

Wieneke B (2015) PIV uncertainty quantification from correlation statistics. Meas Sci Technol 26(7):074002

Winkelmann AE (1983) On the occurrence of mushroom shaped stall cells in separated flow. AIAA paper 1734

Winkelmann AE (1990) Flow field studies behind a wing at low Reynolds number. AIAA paper 1471

Winkelmann AE, Barlow J (1980) Flow field model for a rectangular planform wing beyond stall. AIAA J 18(8):1006-1008

Yon SA, Katz J (1998) Study of the unsteady flow features on a stalled wing. AIAA J 36(3):305-312

Yon SA, Katz J (1998) Cellular structures in the flow over the flap of a two-element wing. J Aircr 35(2):230-232

Zarutskaya T, Arieli R (2005) On vortical flows structures at wing stall and beyond. AIAA paper no. 4913 